\title{
Un camino a la modernidad: Miguel Fisac y la estética de lo popular
}

\section{A way to modernity: Miguel Fisac and popular aesthetics}

\author{
Ramón Vicente Díaz del Campo Martín Mantero \\ Universidad de Castilla-La Mancha
}

Fecha de recepción: 12 de julio de 2017

Fecha de aceptación: 3 de mayo de 2018
Anuario del Departamento de Historia y Teoría del Arte vol. 29-30, 2017-2018, pp. 25-47

ISSN: 1130-5517, eISSN: 2530-3562

http://doi.org/10.15366/anuario2017-2018.29-30.01

\section{RESUMEN}

Miguel Fisac (1913-2006) fue uno de los protagonistas de la recuperación del movimiento moderno en la arquitectura española. Durante la década de los cincuenta su trayectoria profesional destacó, entre otras cuestiones, por la construcción de varios edificios inspirados en la arquitectura tradicional. Estas obras pusieron sobre la mesa diversos elementos para la gestación de una nueva tipología arquitectónica que fue ampliamente utilizada en los años siguientes y despertó un gran interés entre sus compañeros de profesión. La obra de Miguel Fisac es poliédrica, configurada por una intensa actividad constructiva, pero al mismo tiempo rica en aspectos teóricos, en ambas facetas lo popular estuvo muy presente.

\section{PALABRAS CLAVE}

Fisac. Arquitectura popular. Daimiel. Arquitectura moderna. Siglo XX.

\begin{abstract}
Miguel Fisac (1913-2006) was one of the protagonists of the return of modern postulates to Spanish architecture. During the fifties, his professional career stood out, among other things, thanks to the construction of some buildings used of the traditional architecture. Those constructions gathered all the elements for the birth of a new architectural typology which was extensively used in the following years. Most architects were interested in it. Miguel Fisac work are polyhedrons. Is formed by intense constructive activity and at the same time theoretical texts, where the vernacular had great importance.
\end{abstract}

\section{KEY WORDS}

Fisac. Traditional architecture. Daimiel. Modern Architecture. $20^{\text {th }}$ Century.

\section{Los intensos años cincuenta ${ }^{1}$}

En el ecuador del siglo XX el gobierno español intentaba insertarse en un nuevo orden internacional y, al mismo tiempo, pretendía mantener unas características propias que dieran legitimidad al régimen. Buena

\footnotetext{
${ }^{1}$ La realización de este artículo no hubiera sido posible sin la documentación que se conserva en el Archivo de la Fundación Miguel Fisac. Quisiera agradecer a su director Diego Peris Sánchez todas las facilidades que me fueron prestadas.
} 
parte de los cambios que se produjeron en España vinieron de la mano de las nuevas alianzas internacionales con las que el país logró mantenerse en un complejo panorama internacional, convirtiéndose Estados Unidos en uno de sus principales aliados. En este nuevo contexto desde algunas instituciones se apostó por la búsqueda de una imagen moderna e integradora que ayudara al país a entrar en el juego internacional.

Este escenario afectó de lleno al ámbito cultural. En los primeros años del gobierno franquista se había promocionado un arte de corte más académico y tradicional, ahora desde la administración se decidió dedicar más atención a una estética de corte más renovador. Las instituciones culturales buscaron crear una imagen más positiva y moderna en el exterior al tiempo que un grupo de creadores aprovechó la coyuntura para promocionar su arte fuera del país. Todos estos elementos formaron parte de una estrategia política que trataba de convencer al contexto internacional de que España era un país moderno que poseía ciertas peculiaridades, y por ese motivo era gobernada por una dictadura. Este momento de cambio tuvo su reflejo en la mayoría de las manifestaciones artísticas, donde determinados grupos y artistas de vanguardia promovieron un nuevo arte de corte internacional, pero al que se dotó de ciertos tintes teóricos que lo conectaban con episodios del pasado español ${ }^{2}$.

Al final de los años cuarenta empezamos a ver algunos ejemplos de jóvenes arquitectos que se plantearon si el escenario por el que se movía entonces la arquitectura española era el camino que debían seguir. Para algunos era necesario dejar atrás la arquitectura de estado basada en un estilo imperial ${ }^{3}$ y en revival tradicionales ${ }^{4}$ que se habían promovido desde diversas instituciones y organismos. Los tiempos habían cambiado y era necesario un debate y las entidades oficiales tuvieron la habilidad de plantear en público el problema. No solo no se pusieron impedimentos, todo lo contrario, se apoyó y se incentivó.

En mayo de 1949 se celebró la V Asamblea Nacional de Arquitectura en las ciudades de Barcelona, Valencia y Palma de Mallorca. La reunión fue convocada por la Dirección General de Arquitectura y el Consejo Superior del Colegio de Arquitectos, y durante una semana se debatieron cuatro bloques en torno a los que giró la asamblea ${ }^{5}$. En las ponencias y coloquios se pudo ver cuál era la situación del ejercicio de la profesión arquitectónica en España. Tal fue el interés hacia la asamblea que la Revista Nacional de Arquitectura y el Boletín de la Dirección General de Arquitectura recogieron en sus páginas varias de las ponencias presentadas ${ }^{6}$, donde se expusieron múltiples enfoques que abarcaron desde la postura de escepticismo de José Fonseca ${ }^{7}$ hasta la propuesta de Juan de Zavala que abogó por la búsqueda de un nuevo camino motivado por al agotamiento del modelo oficial: "esto se revela simplemente con ojear las revistas extranjeras que nos llegan: parece que no sólo el texto, sino las imágenes hablan en otro idioma"8.

Los arquitectos que se titularon tras la guerra y que iniciaron su carrera con obras acordes a tendencias historicistas comenzando a introducir lenguajes de modernidad en el país. El aislamiento sufrido en la década de los cuarenta fue uno de los principales factores que motivó la desconexión con lo que se forjaba fuera de España. Las revistas extranjeras de arquitectura apenas llegaban, situación que empezó a cam-

\footnotetext{
2 Véase Julián DíAz SÁnchez, El triunfo del informalismo: la consideración de la pintura abstracta en la época de Franco, Madrid, Metáforas del Movimiento Moderno, 2000.

3 Carmen RÁBANOS FACI, "Estética de la representación en los regímenes autoritarios (el marco escenográfico arquitectónico del nazismo, fascismo y franquismo)", Emblemata, no 12 (2006), pp. 275-288.

4 Antonio Pizza, "Malos tiempos para la lírica. Esperanza y desesperanza en la Europa de posguerras" en Los años 50: la arquitectura española y su compromiso con la historia, Pamplona, Universidad de Navarra, 2000, pp. 56-57.

5 Carlos SAMBRICIO, "De la arquitectura del nuevo estado al origen de nuestra contemporaneidad: el debate sobre la vivienda en la década de los cincuenta", Ra. Revista de arquitectura, $\mathrm{n}^{\circ}$ 4, (2000), pp. 75-76.

6 Ana EsteBAn, “¿Modernidad o tradición? El papel de la RNA y el BDGA en el debate sobre las tendencias estilísticas de la arquitectura española" en Los años 50: la arquitectura española y su compromiso con la historia, Pamplona, Universidad de Navarra, 2000, pp. 242-243.

7 Jose FonsECA, “Tendencias actuales de la Arquitectura”, Boletín de la Dirección General de Arquitectura, no 11 (1949), pp. 3-5.

8 Juan Zavala, “Tendencias actuales de la Arquitectura”, Revista Nacional de Arquitectura, no 90 (1949), p. 36.
} 
biar con la llegada de los años cincuenta. Coincidiendo con ese periodo de apertura varios arquitectos españoles aprovecharon la oportunidad para realizar diversos viajes al extranjero con la intención de entrar en contacto con otra realidad y explorar nuevos caminos para huir del punto muerto en la que se encontraba el panorama español ${ }^{9}$ : Cabrero viaja a Centroeuropea e Italia, Vázquez Molezún fue a Roma de 1949 a 1952 y García de Paredes visitó distintos países europeos de 1950 a 1952 . Un buen número de aquellos viajes fueron financiados por organismos oficiales y tenían como principales destinos países europeos ${ }^{10}$. Miguel Fisac efectuó un recorrido por varias zonas de Europa en 1949. Durante aquellos años tenía una estrecha relación laboral con el Consejo Superior de Investigaciones Científicas, para el que estaba realizando el proyecto del Centro de Investigaciones Biológicas de los Patronatos Cajal y Ferrant. Como parte del estudio del programa para laboratorios viajó por diversos centros de investigación europeos para conseguir información directa sobre los elementos necesarios para la estabulación de animales: ratas, ratones, cobayas, etc., proporcionando al arquitecto la ocasión de visitar distintas ciudades europeas ${ }^{11}$. Fisac se encontró con interesantes propuestas arquitectónicas, descubriendo la arquitectura nórdica y en concreto las obras de Arne Jacobsen y Erik Gunnar Asplund ${ }^{12}$.

\section{Fisac y la apuesta por lo popular en el debate sobre el estado de la arquitectura}

De todos los tipos de arquitectura, la arquitectura popular, por la manera de crearse y por su íntima razón de ser, tiene una humanidad efectiva que es, precisamente, la que es necesario recoger, no para integrarla en lo que hoy llamamos arquitectura moderna, sino para esa otra arquitectura que venga después, que tenga una raíz humana, que es lo que no tiene la actual ${ }^{13}$.

En el arranque de la segunda modernidad española tuvieron una especial importancia las revistas profesionales que se convirtieron en el medio ideal para la difusión de nuevas ideas y propuestas. El arquitecto manchego y sus obras aparecían con frecuencia en estas publicaciones, siendo uno de los protagonistas del momento. Se divulgó su obra como paradigma de los nuevos tiempos, asimismo tuvo una intensa participación en el debate sobre la renovación de la arquitectura española. Su postura fue clara, el arquitecto planteaba una arquitectura moderna usando como base la arquitectura popular pero evadiendo la interpretación que algunas propuestas teóricas hacían buscando una manera española. Fisac no fue el único que inició esta vía del uso de lo vernáculo como camino hacia la modernidad, otros arquitectos y teóricos tenían planteamientos parecidos, convirtiéndose el uso de lo tradicional en un elemento clave en el proceso de renovación del escenario arquitectónico español.

El debate sobre el papel de lo popular es una constante en la historia de la arquitectura española donde buena parte de los autores de cada momento realizaron diversas aportaciones tanto a nivel teórico como constructivo. Desde las últimas décadas del siglo XIX, especialmente con la aparición de la Institución Libre de Enseñanza, se inició un proceso de descubrimiento y estudio del arte tradicional que continuó en las primeras décadas del siglo XX con el regionalismo y la aparición del movimiento moderno ${ }^{14}$. En los

\footnotetext{
9 Antón CAPITEl, Arquitectura española años 50-años 80, Madrid, Dirección General de arquitectura, 1986. p. 28.

10 Ángel Urrutia, Historia de la arquitectura española, Madrid, Cátedra, 1997, p. 516.

11 El viaje se llevó a cabo durante los meses de noviembre y diciembre de 1949 visitando las ciudades de Ginebra, Berna, Zurich, Basilea, Paris, Estocolmo, Uppsala, Gotemburgo, Mälmo, Copenhague, Ámsterdam, La Haya y Bruselas.

12 CApitel, 1986, p. 28.

13 Intervención de Miguel Fisac en la Sesión de Crítica de Arquitectura dedicada a la arquitectura popular en 1953, recogida en Gabriel Alomar, "Valor actual de las arquitecturas populares. Aplicación particular a la arquitectura popular de los tipos mediterráneos", Revista Nacional de Arquitectura, no 37 (1953), pp. 35-50.

14 Esther AlAmARCHA, "El descubrimiento y la puesta en valor de la arquitectura popular: de Fernando García Mercadal a Luis Feduchi" en Lecciones de los maestros: aproximación histórico-crítica a los grandes historiadores de la arquitectura española, Zaragoza, Institución Fernando el Católico, 2011, p. 188.
} 
primeros años del franquismo la arquitectura popular volvió a tener un papel relevante en la reflexión que se hizo sobre la práctica arquitectónica como se puede ver analizando la actividad de algunos de los principales organismos del nuevo gobierno como la Dirección General de Regiones Devastadas o el Instituto Nacional de Colonización. En estas instituciones se veía en lo popular la respuesta a problemas particulares y concretos. A través de sus publicaciones y actuaciones podemos analizar las diferentes opciones de acercarse a la arquitectura tradicional que van desde la interpretación costumbrista hasta la perfecta interrelación entre propuestas vernáculas y modernas.

El organismo que aglutinó un mayor número de revistas fue la Dirección General de la Arquitectura ${ }^{15}$ que editó varias publicaciones, dos de ellas bajo la batuta de Carlos de Miguel: Revista Nacional de Arquitectura y Boletín de la Dirección General de Arquitectura ${ }^{16}$. El Boletín se convirtió en punto de encuentro para los descontentos con la situación de estancamiento que vivía la arquitectura ${ }^{17}$. Gabriel Alomar, Francisco Cabrero y José Marta Sostres, junto a Miguel Fisac, fueron algunas de las firmas que manifestaron aquel desencanto. En el año 1947 aparecía en sus páginas un editorial titulado Arquitectura Española que hacía una llamada de atención sobre el alto grado de oficialismo existente en la arquitectura europea y la necesidad imperante de una reflexión por parte de los arquitectos españoles ${ }^{18}$.

Fueron apareciendo más opiniones críticas, algunas planteaban la necesidad de un cambio de estilo en el panorama español dejando atrás la arquitectura de corte escurialense. Un sector más reducido apuntaba incluso a la necesidad de mayor libertad expresiva para dar lugar a una nueva arquitectura acorde con los nuevos tiempos ${ }^{19}$. Uno de los primeros textos con un marcado carácter renovador fue publicado en el mes de junio de 1948 y es considerado por varios autores como el punto de partida en la búsqueda de una nueva arquitectura: se trata del texto de Miguel Fisac titulado "Lo clásico y lo español" que dictó sentencia en contra de determinada arquitectura monumental.

Tomar El Escorial como único modelo, tratar de copiarlo o inspirarse en él para resolver los cien mil pequeños problemas arquitectónicos que nos depara la dura realidad de hoy, es tan ridículo como que en un ejército moderno todos los soldados quieran ser Napoleón. Lo español y su manera de ver y sentir lo clásico está en toda la arquitectura española. No en este edificio o en aquél, sino en muchos; en el alma de los de Santillana y de los de Ronda, de los de Albarracín y de los de Lerma. Pero no está allí fuera; no es el escudo, ni la ventana de esquina, ni la ménsula; no está en un escaparate, para que nosotros lo cojamos cómodamente con nuestra "Leica" al pasar en coche. Está más dentro; no se entrega tan fácilmente. Exige de nosotros trabajo y entusiasmo, amor por la arquitectura, que es algo que quizás no nos sobra ${ }^{20}$.

Ese mismo año aparecía otro texto del arquitecto titulado "Las tendencias estéticas actuales"21. En sus palabras, al igual que en casos anteriores, se apuesta en la apuesta por la asimilación de las lecciones de lo popular como medio para alcanzar la poética de la modernidad. El arquitecto incidió en la importancia del entorno (no sólo físico sino cultural) para realizar una arquitectura honesta con los nuevos tiempos:

15 La Dirección General de Arquitectura fue fundada por Ley el 23 de septiembre de 1939 con la intención de incorporar al Estado un organismo de control de la Arquitectura y los Arquitectos.

16 Felipe Asenjo Álvarez, La nueva arquitectura. La contribución de las publicaciones periódicas de la Dirección General de Arquitectura (1948-1958), Tesis Doctoral, Madrid, Universidad de Alcalá de Henares, 2015, p. 257.

17 Víctor PÉREz EsCOLANO, "Arquitectura y política en España a través del Boletín de la Dirección General de Arquitectura (1946-1957)", Ra. Revista de Arquitectura, Vol. 15 (2013), p. 28.

18 RED, “Arquitectura española", Boletín de Información de la Dirección General de Arquitectura, no 5 (1947), p. 3.

19 Ana EstebAn, “¿Modernidad o tradición? El papel de la RNA y el BDGA en el debate sobre las tendencias estilísticas de la arquitectura española" en Los años 50: la arquitectura española y su compromiso con la historia, Pamplona, Universidad de Navarra, 2000, p. 242.

20 Miguel FISAC, “Lo clásico y lo español”, Revista Nacional de Arquitectura, no 78 (1948), pp. 197-198.

21 Miguel FisAC, "Las tendencias estéticas actuales", Boletín Dirección General de Arquitectura, no 9 (1948), pp. 21-25. 
La casita que se construye en un lugar sigue siempre no sólo ligada al paisaje por vínculos de clima, de color y de ambiente físico, sino también a otros morales, etnológicos, de idiosincrasia de los habitantes de esa región. Esa idiosincrasia ha creado espontáneamente una arquitectura popular -riquísima en España-; copiarla alegremente acarrear los tristes resultado que tan abundantemente conocemos, pero desconocerla y olvidarla es privarse de un gran medio, si queremos que la nueva arquitectura sea humana, para hombres que tiene unas necesidades físicas que satisfacer, pero, además y sobre todo, que tiene alma ${ }^{22}$.

Los artículos se fueron sucediendo ${ }^{23}$ y el debate tomó tal dimensión que uno de los bloques de la $\mathrm{V}$ Asamblea Nacional de Arquitectos ${ }^{24}$ llevó por título Tendencias estéticas de la arquitectura moderna, convirtiéndose en el que más interés despertó de los propuestos a debate ${ }^{25}$. En la asamblea de 1949 se dejó atrás la arquitectura con determinadas connotaciones ideológicas impuesta tras la contienda, eran tiempos de cambios. Miguel Fisac presentó una ponencia en la que el arquitecto achacó falta de verdad en la producción nacional y animó a sus compañeros a dejar de lado los pastiches y buscar en los orígenes de la verdadera historia:

Copiar el arte popular o clásico español conduce al folklore o a la españolada. Extraer su esencia, saber sacar esos ingredientes de verdad, de modestia, de alegría, de belleza que tiene, sería encontrar el camino de una nueva Arquitectura y, en general de un arte nuevo. Manuel de Falla lo consiguió en música. ¿Por qué no seguir su ejemplo? ${ }^{26}$

Esa sensación de estancamiento que estaba en el trasfondo de la arquitectura española se empezó a plasmar en las revistas especializadas. Los artículos, obras, concursos, congresos y exposiciones que aparecían en sus páginas permiten identificar cuáles eran los acontecimientos más relevantes, el origen de nuevas ideas y definir los límites de esa intensa investigación. A principios de la década de los cincuenta las revistas cumplieron con varias funciones: facilitaron la configuración de un discurso de modernidad arquitectónica, sirvieron de cauce para el intercambio ideológico y de discusión, dieron a conocer aquellos episodios más relevantes que se producían en el panorama nacional e internacional y se usaron de elemento de difusión de la producción nacional en el extranjero ${ }^{27}$.

Dentro de las revistas de arquitectura de la época tuvo especial relevancia la Revista Nacional de Arquitectura que desde 1941 dependía de la Dirección General de Arquitectura con Pedro Muguruza al frente. La tendencia de la revista cambió completamente tras la guerra y publicitó en sus páginas una arquitectura historicista en la que no se hizo concesiones a la modernidad ni a las vanguardias extranjeras ${ }^{28}$. Es

22 Ibidem, p.23

23 Entre las distintas aportaciones al debate destacaron: Gabriel AlOMAR, "Sobre las tendencias estilísticas de la arquitectura española actual”, Boletín de la Dirección General de Arquitectura, no 7 (1948), p. 11; Francisco de Asís CABRERO, "Comentario las tendencias estilísticas", Boletín de la Dirección General de Arquitectura, no 8 (1948), p. 8; José Fonseca, "Tendencias actuales de la Arquitectura", Boletín de la Dirección General de Arquitectura no 11 (1949), pp. 9-13; Juan de ZABALA, "Tendencias actuales en Arquitectura", Revista Nacional de Arquitectura, no 90 (1949), pp. 264-269; Luis MoyA, "Tradicionalistas, funcionalistas y otros", Revista Nacional de Arquitectura, no 102 (1950), p. 261; Francisco MituAns, "Pero en nuestras calles no crece la hiedra", Boletín de la Dirección General de Arquitectura, nº14 (1950), pp. 6-9; Mariano Rodríguez AviAL, "Arquitectura moderna y deshumanización del arte", Boletín de la Dirección General de Arquitectura, nº18 (1951), pp. 9-14 y José María SosTRES, “La arquitectura monumental", Revista Nacional de Arquitectura, no 113 (1951), pp. 24-28.

${ }^{24}$ La V Asamblea Nacional de Arquitectura se celebró en mayo de 1949 en las ciudades de Barcelona, Valencia y Palma de Mallorca. La reunión fue convocada por la Dirección General de Arquitectura y el Consejo Superior del Colegio de Arquitectos.

25 SAmbricio, 2000, pp. 75-76.

${ }^{26}$ Miguel FiSAC, “Estética de Arquitectura”, Boletín de la Dirección General de Arquitectura, n ${ }^{\circ} 11$ (1949), p. 14.

27 Isabel DURÁ GÚRPIDE, "La revista como referencia, testigo y difusora de la nueva arquitectura escolar" en Las revistas de arquitectura (1900-1975): crónicas, manifiestos, propagandas. Pamplona, T6) Ediciones, 2012, p 464.

28 Antón CAPITEL, "Notas sobre los avatares históricos de la revista Arquitectura como medio de difusión de la innovación arquitectónica”, Informes de la construcción, $\mathrm{n}^{\text {0 }} 60$ (2008), pp. 45-48. 
muy significativo que a partir de 1948 la revista vuelva a pertenecer al Colegio de Arquitectos de Madrid e inicie una nueva etapa bajo la dirección de Carlos de Miguel. Su formato y el aspecto se modificaron, y rápidamente aparecieron textos y proyectos de los arquitectos jóvenes del momento: Cabrero, Aburto, Coderch, de la Sota, Fisac, Saenz de Oiza, Corrales y Molezún, etc. ${ }^{29}$ Una de las secciones fijas dentro del contenido de la publicación fueron las conocidas como "Sesiones de Crítica de Arquitectura" (1950-1964), reuniones de debate organizadas y publicadas por la revista donde se presentaban a debate numerosos temas de la actualidad. El ciclo se inauguró en 1950 con un debate dedicado al edificio de la ONU en Nueva York. Esta primera asamblea se planteó con la misma estructura que tuvieron las siguientes: un ponente invitado por la organización realizaba una exposición del tema elegido pasando el turno, a continuación, al resto de asistentes para que expresaran su opinión. De esta forma, cada sesión generó una mesa redonda en la que se debatieron los argumentos presentados ${ }^{30}$. La mayoría de las Sesiones de Crítica se dedicaron a cuestiones directamente relacionadas con el ámbito español, fueron contadas las reuniones dedicadas a temas extranjeros ${ }^{31}$. Fisac tuvo un papel destacado en las mismas, ya que participó en un importante número de reuniones y se dedicaron sesiones a la presentación de sus obras como la Iglesia de los Padres Dominicos de Valladolid ${ }^{32}$, la Parroquia de la Coronación en Vitoria ${ }^{33}$ y los edificios para el Centro de Formación del Profesorado Laboral ${ }^{34}$.

Fruto de estas "Sesiones de Crítica de Arquitectura" surgió el denominado Manifiesto de la Alhambra. Se trató de una reunión extraordinaria en la que un grupo de arquitectos se retiró durante los días 14 y 15 de octubre de 1952 para "meditar sobre las bases de una nueva arquitectura española"35. La reunión, realizada en Granada, generó unas conclusiones cuya redacción definitiva fue realizada por Fernando Chueca Goitia. La tertulia pretendía basarse en los principios de la arquitectura hispanoárabe como punto de partida para buscar nuevos espacios constructivos ${ }^{36}$. Los arquitectos participantes pretendían encontrar en La Alhambra el paradigma de una nueva arquitectura española que abandonara definitivamente los supuestos herrerianos.

El manifiesto tuvo una repercusión limitada debido a múltiples factores como la heterogeneidad de sus firmantes, lo confuso de sus conclusiones o el no seguimiento de sus principios por parte de algunos arquitec$\operatorname{tos}^{37}$. Los asistentes a la reunión fueron divididos en varios grupos ${ }^{38}$ y a cada uno de ellos se les encargó que analizaran distintos valores del monumento granadino. En la Revista Nacional de Arquitectura se adelantaron

29 Asenjo Álvarez, 2015, p. 260.

30 Esteban, 2000, p. 245.

31 Enrique Solana, "Granada, 1953. El Manifiesto de la Alhambra", Revista de Edificación RE, no 17 (1994), p. 71.

${ }^{32}$ Miguel FisAc, "Sesión de Crítica de Arquitectura dedicada a la iglesia de los PP. Dominicos en Valladolid", Revista Nacional de Arquitectura 157, 1955, pp. 10-19.

${ }_{33}$ Carlos de Miguel, "Sesión de Crítica de Arquitectura. Las nuevas parroquias de Vitoria", Revista Nacional de Arquitectura, n 196 (1958), pp. 1-19.

${ }^{34}$ Miguel FISAC, "Conjunto de edificios para formación del profesorado de enseñanza laboral en la Ciudad Universitaria", Revista Nacional de Arquitectura, $\mathrm{n}^{\circ} 203$ (1958), pp. 3-10.

${ }^{35}$ Solana, 1994, p. 72.

${ }^{36}$ Los asistentes a la Sesión de la Alambra fueron: Rafael Aburto, Pedro Bidagor Lasarte, Francisco Cabrero, Eusebio Calonge, Fernando Chueca, José Antonio Domínguez Salazar, Rafael Fernández Huidobro, Miguel Fisac, Damián Galmés, Luis García Palencia, Fernando Lacasa, Emilio Larrodera, Manuel López Mateos, Ricardo Magdalena, Antonio Marsá, Carlos de Miguel, Francisco Moreno López, Juana Ontañón, José Luis Picardo, Francisco Prieto Moreno, Mariano Rodríguez Avial, Manuel Romero, Secundino Zuazo y José Luis Aranguren.

37 Alberto GRIJALBA, "Del campo a la ciudad. Los frenéticos cincuenta" en Arquitectura, ciudad e ideología antiurbana. Pamplona, T6 Ediciones, 2002, pp. 110-111.

${ }^{38}$ Los grupos fueron: Formas (Pedro Bidagor, Jose A. Domínguez Salazar, Damián Galmés. Emilio Larredera, Ricardo Magdalena, Antonio Marsá, Manuel Romero y Secundino Zuazo), Construcciones (José Luis Aranguren, Rafael Fernández Huidobro, Luis García Palencia, Francisco Moreno López y Mariano Rodriguez Avial), Jardines (Fernando Chueca, Miguel Fisac, Fernando Lacasa y Francisco Prieto Moreno) y Decoración (Rafael Aburto, Fráncico Cabrero, Eusebio Calonge, Carlos de Miguel y José Luis Picardo). 
algunas de las opiniones y conclusiones del singular encuentro, entre ellas encontramos la del arquitecto manchego donde se puede ver la importancia que la arquitectura hispanoárabe tendrá en su propuesta estética:

Yo veo en la Alhambra, como elemento arquitectónico esencial, el aire, el aire quieto. Después el agua; agua en movimiento, como expresión de vida. Las superficies que limitan este aire quieto son las que dan lugar a las formas espaciales. La vegetación se incorpora a todo este conjunto. El dar el principal papel en arquitectura al aire, al agua, a la naturaleza, exige del arquitecto una posición de humildad amorosa. Los arquitectos de la Alhambra nos dan un gran ejemplo. Han obrado humildemente ${ }^{39}$.

Las aportaciones de Miguel Fisac no se limitaron a las revistas especializadas. Durante aquellos años tuvo una intensa colaboración en varios diarios, dejándonos una amplia y valiosa literatura con sus artículos en el diario $A B C$, el dominical Blanco y Negro o el magazín La Actualidad Española ${ }^{40}$. Se trató de opiniones profesionales donde analizaba, con un sentido divulgador, la arquitectura de determinadas ciudades, temas profesionales de arquitectura, reflexiones sobre el concepto de belleza, el paisaje, el agua... De igual manera también encontramos recogidas en prensa sus opiniones vertidas en multitud de conferencias, mesas redondas y actos culturales. En todas estas propuestas fue también recurrente su defensa de la arquitectura popular. Esta faceta teórica se complementa con su intensa labor como escritor que tuvo sus frutos en varios libros publicados, destacando La Molécula Urbana ${ }^{41}$ donde planteó una singular propuesta urbanística ejemplificada en la comarca natural de La Mancha, así como Mi estética es mi ética ${ }^{42}$ o Carta a mis sobrinos ${ }^{43}$. El arquitecto disertó en varias de sus publicaciones sobre el valor de la arquitectura popular y en espacial sobre la manchega. El texto más conocido es el que lleva por título "Arquitectura popular manchega", tratándose de su discurso de ingreso como miembro del Instituto de Estudios Manchegos ${ }^{44}$. En este estudio, como en la pequeña publicación La Arquitectura popular española y su valor ante la del futuro $^{45}$, el arquitecto planteó de nuevo un alegato de las virtudes que presenta este tipo de propuesta entendida como "la arquitectura que hace el pueblo y el tiempo" 46.

\section{De la teoría a la práctica: la arquitectura popular como materia de la modernidad}

Durante los primeros años de la década de los cincuenta, periodo de experimentación en la búsqueda de un estilo personal, Miguel Fisac realizó varios proyectos en su tierra natal donde se enfrentó a una nueva definición de la arquitectura popular a través de la utilización de una serie de elementos típicos como tejas, tapial, encalados, tinajas, etc. pero con una forma totalmente distinta de emplearlos, consiguiendo despegarse de las interpretaciones triviales y folclorista de lo popular para alcanzar el tono poético de modernidad que caracterizó buena parte de su producción.

39 "Sesión de crítica de arquitectura celebrada en la Alhambra los días 14 y 15 de octubre de 1952", Revista Nacional de Arquitectura, $\mathrm{n}^{\mathrm{o}} 136$ (1953), p. 20.

40 Alberto Ruiz Colmenar, "Fisac, Periodista. Difusión de temas de arquitectura en la prensa no especializada" Actas del I Congreso Pioneros de la Arquitectura Moderna Española: Vigencia de su pensamiento y obra, Madrid, Fundación Alejandro de la Sota, 2014, pp. 863-874.

41 Miguel FisAC, La Molécula Urbana. una propuesta para la ciudad del futuro, Madrid, Ediciones y Publicaciones Españoles, 1969.

42 Miguel Fisac, Mi Estética es mi ética, Ciudad Real, Museo Provincial, 1982.

43 Miguel Fisac, Carta a mis sobrinos, Ciudad Real, Fundación Miguel Fisac, 2010.

44 Miguel FISAC, “Arquitectura popular manchega", Cuadernos de estudios manchegos, ${ }^{\circ} 16$ (1985), pp. 17-54. El texto fue reeditado años después por parte del Colegio de Arquitectos de Ciudad Real para conmemorar la adquisición del archivo personal del arquitecto: Miguel FISAC, Arquitectura Popular manchega, Ciudad Real, Colegio Oficial de Arquitectos, 2005.

45 Miguel FISAC, La Arquitectura popular española y su valor ante la arquitectura del futuro, Madrid, Ateneo, 1952.

46 FISAC, 1985, p. 17. 
Fisac no fue el único que inició esta vía de utilización de lo vernáculo como camino hacia la modernidad, otros autores del momento siguieron rutas con soluciones y planteamientos de lo más diverso y dispar. Arquitectos como Fernández del Amo, Cabrero, Bohigas y Alejandro de la Sota realizaron diversas propuestas que buscaban el mestizaje entre lo tradicional y lo moderno ${ }^{47}$. Los planteamientos fueron distintos: por ejemplo, Fernández del Amo en sus poblados de colonización moderniza la tradición, mientras que otros autores como Coderch, "tradicionalizaron" la modernidad. Se trata de una nueva revisión del recurrente debate entre tradición y modernidad que fue uno de los más repetidos en los planteamientos de la arquitectura española del siglo XX. Además existe el precedente del uso que se hizo de lo vernáculo durante la década de los años treinta por parte de algunos arquitectos del GATCPAC (Grupo de Arquitectos y Técnicos Catalanes para el Progreso de la Arquitectura Contemporánea), principalmente Sert, Torres Clavé o Subirana que se habían interesado por la cuestión de la arquitectura popular. Este interés se incrementó tras la celebración del IV Congreso Internacional de Arquitectura Moderna (CIAM) en 1933. En él se apostó, bajo el liderazgo de Le Corbusier, por la adopción de elementos sacados de la tradición arquitectónica del Mediterráneo. Al congreso asistieron algunos de los arquitectos españoles del GATEPAC, pudiéndose observar un gran interés hacia lo vernáculo que quedó reflejado en los siguientes números de la revista $A$.C. así como en algunas de sus propuestas.

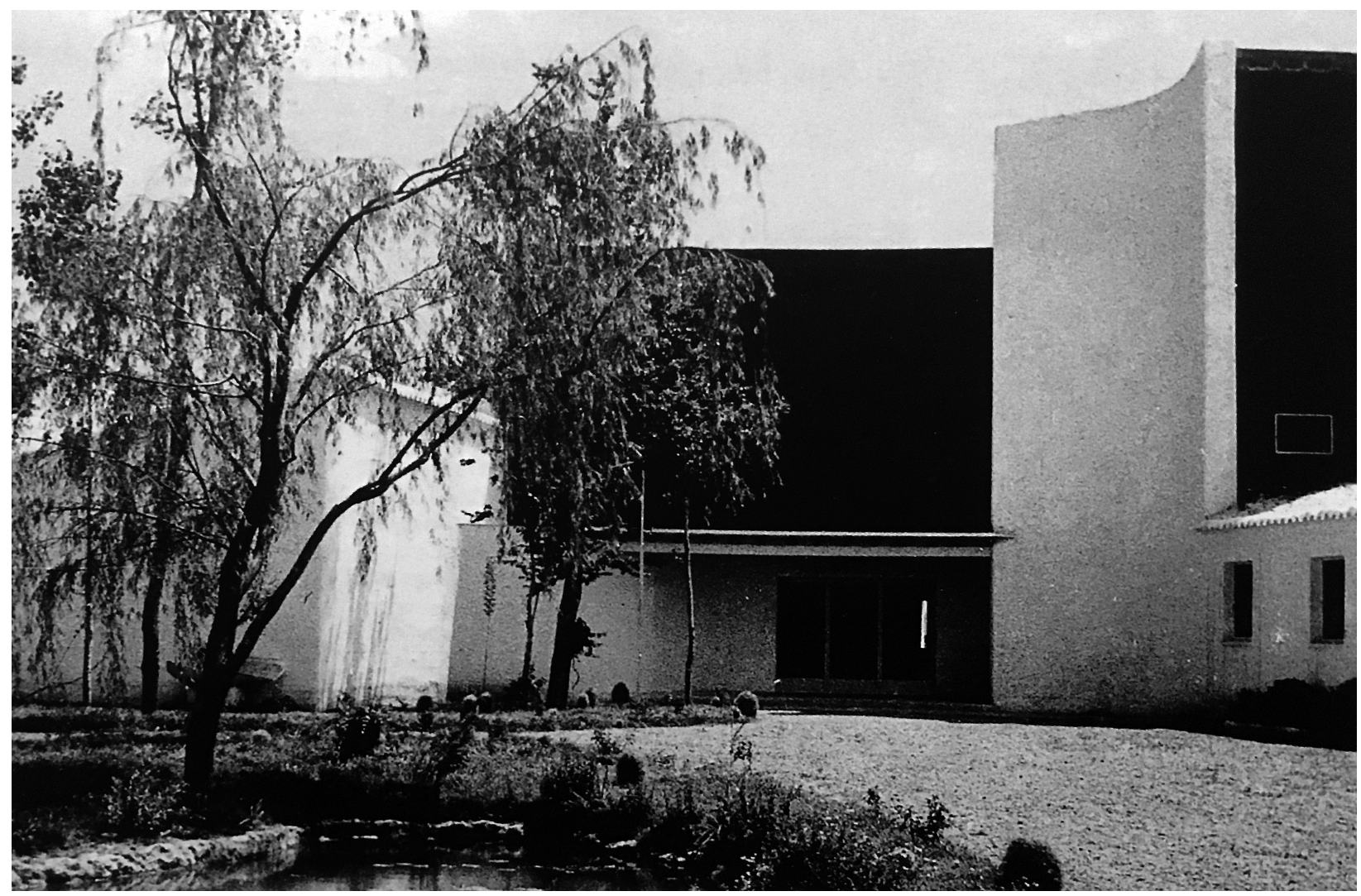

Fig. 1. Miguel FISAC, Instituto Laboral de Daimiel, 1950-1953. Daimiel (Ciudad Real). Archivo de la Fundación Miguel Fisac.

47 Alberto GriJalbA, "Equívocos, amigos y dos puentes. Italia-España” en Modelos alemanes e italianos para España en los años de la postguerra, Pamplona, Universidad de Navarra, 2004, p. 20 (pp.13-20). 
El uso de lo popular como principio estético fue constante en Miguel Fisac a lo largo de las distintas fases de su trayectoria profesional. Varias de sus obras, construidas principalmente durante la década de los cincuenta, estaban basadas en elementos extraídos de lenguajes populares como en el Instituto Laboral de Daimiel (1950-1953), el Pabellón de Ciudad Real en la Feria del Campo de Madrid (1953), el Mercado de Abastos de Daimiel (1955), la Casa de Cultura de Ciudad Real (1957) y la Vivienda para la familia Pozuelo en Daimiel (1958), entre otros. Sin embargo, al hablar de arquitectura popular en relación con él podríamos cometer el error de pensar en exclusiva en la arquitectura popular manchega. El arquitecto realizó varias construcciones inspirándose en propuestas de distintas regiones de España como la vivienda familiar (1959) y una parroquia en Canfranc (1965) en la provincia de Huesca, una vivienda para la familia Larragueta en Ortigosa del Monte en Segovia (1955) o una serie de viviendas en Costa de los Pinos en Mallorca realizadas durante los años sesenta ${ }^{48}$.

Probablemente la obra más popular de todas las anteriormente citadas sea el Instituto Laboral de Daimiel (Ciudad Real). En 1950 Miguel Fisac comenzó la construcción del primer edificio considerado por él mismo como moderno ${ }^{49}$. En él se visibilizan una serie de cambios en su trayectoria como la preocupación por el espacio, la utilización de técnicas de tradicionales, el protagonismo de los detalles, el diseño de la totalidad del edificio o las ordenaciones de los elementos que lo configuran. Juan Daniel Fullaondo describe estos años como "de experimentación" 50 y podemos rastrear en esta época las diferentes influencias en la obra del arquitecto que se pueden resumir en varios ejes: arquitectura hispanoárabe, japonesa, nórdica y popular (fig. 1).

A través del decreto de 10 de agosto de 1950 se autorizó por parte del Ministerio de Educación Nacional la creación en Daimiel (Ciudad Real) de un Centro de Enseñanza Media y Profesional de modalidad Agrícola y Ganadera ${ }^{51}$. El proyecto de los institutos laborales surgió de la política económica y educativa del gobierno de Francisco Franco durante su primera etapa. El nuevo gobierno, surgido tras el enfrentamiento bélico, vio en la agricultura el motor económico para dejar atrás la dura posguerra. En realidad, fue más bien una necesidad, ya que era prácticamente la única opción que tenía con casi el 50\% de la población activa residiendo en el ámbito rural. Por este motivo, desde el ministerio se ideó un programa educativo para ese importante porcentaje de población del país que residía lejos de los núcleos urbanos más importantes y que apenas tenía acceso a una educación secundaria ${ }^{52}$. El nuevo Bachillerato se impartió en los denominados popularmente como Institutos Laborales que se fueron instalando en las principales poblaciones de las comarcas rurales. Desde el gobierno no se dejó nada al azar y se diseñó un Plan Nacional para la Construcción de Institutos Laborales que estableció de forma rigurosa la ubicación de los centros y la modalidad que se ofertaría en cada lugar: agrícola-ganadera, industrial-minera o marítimo-pesquera ${ }^{53}$.

Cuando comenzó la construcción de los primeros centros no existían en la España franquista referentes cercanos en cuanto a arquitectura docente. La educación en España había dependido históricamente de iniciativas privadas (órdenes religiosas mayoritariamente) y su lenguaje arquitectónico grandilocuente estaba pensado más desde la representatividad de la institución que desde necesidades educativas reales. En la década de los veinte se produjo un primer intento hacia la depuración del lenguaje arquitectónico educativo encabezado por el arquitecto Antonio Flórez que organizó un gabinete especializado en arquitectura escolar, labor

\footnotetext{
48 ApARICIO, 2016, p. 84.

49 Alfonso CAlero, "Miguel Fisac: La arquitectura es un trozo de aire humanizado", Añil, n o 14 (1998), p. 46.

50 Juan Daniel Fullaondo, Miguel Fisac, Madrid, Dirección General de Bellas Artes, 1972, p. 8.

51 BOE de 14 de septiembre de 1950, nº 257, p. 3967.

52 Ana Esteban Maluenda, "Tradición versus tecnología. Un debate tibio en las revistas españolas" en Arquitectura, ciudad e ideología antiurbana, Pamplona, T6 Ediciones, 2002, pp. 97-106.

53 Iñaki Berguera, "Institutos laborales: de la teoría a la práctica" en Los años 50: La arquitectura española y su compromiso con la historia, Pamplona, T6 Ediciones, 2002. pp. 195-207.
} 


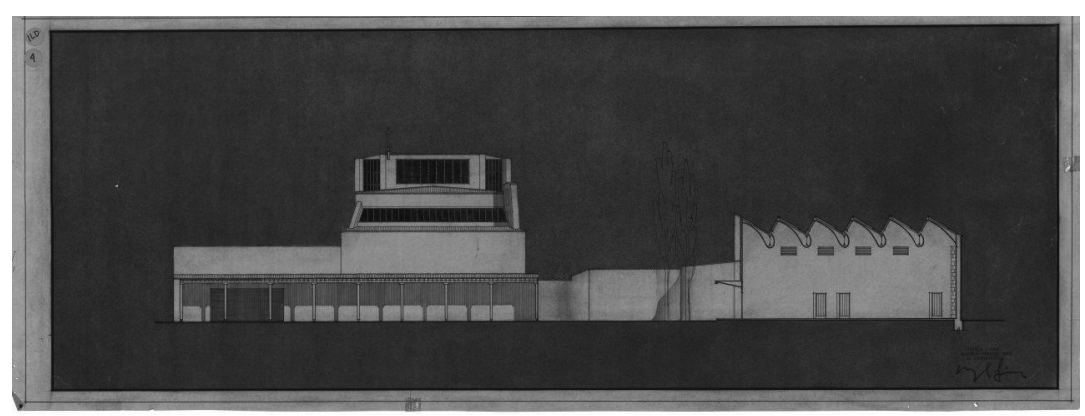

Fig. 2. Miguel FISAC, alzado de edificio para Instituto Laboral en Daimiel, 1950. Archivo de la Fundación Miguel Fisac.

que continuó posteriormente Bernardo Giner de los Ríos ${ }^{54}$. Tras el paréntesis provocado por la guerra se llegó sin logros significativos a la década de los cincuenta. La arquitectura escolar se convirtió en un campo para la experimentación arquitectónica, especialmente los Institutos Laborales. Fisac se convirtió en un pionero y referente de la nueva arquitectura docente. La construcción del edificio daimieleño puso sobre la mesa todos los elementos que presidieron la gestación de una nueva tipología arquitectónica que fue ampliamente utilizada en años venideros y despertó un gran interés entre los compañeros de profesión ${ }^{55}$. En 1954 desde el Ministerio de Educación se planteó la necesidad de convocar un Concurso Nacional entre arquitectos para proyectar las futuras construcciones de institutos laborales ${ }^{56}$. El concurso resultó revelador por los precedentes, por los arquitectos que participaron y por la obtención de buenos resultados. Carlos de Miguel, director de la Revista Nacional de Arquitectura, pidió a Fisac publicar en la revista un artículo sobre el Instituto de Daimiel para orientar a los que se presentaran ${ }^{57}$.

Las primeras propuestas y bocetos del edificio las encontramos fechadas en febrero de $1950^{58}$, aunque el proyecto definitivo fue presentado por el Fisac al Ministerio de Educación Nacional para su aprobación el 30 de abril de $1951^{59}$, siendo aceptado pocos días después por el arquitecto delegado de la Junta Facultativa de Construcción Civiles ${ }^{60}$ (fig. 2). El Instituto Laboral de Daimiel se construyó en unos terrenos a las afueras de la localidad manchega, en una parcela a espaldas del recién creado Parque Municipal con una superficie de $11.550 \mathrm{~m}^{2}$ que fueron cedidos por el ayuntamiento de la localidad después de superar cierta oposición por parte de las autoridades municipales ${ }^{61}$.

El arquitecto planteó como uno de los principales objetivos del proyecto la creación de una serie de ambientes donde fuera posible realizar unas determinadas actividades. El programa propuesto para el Instituto de Daimiel estaba formado por cinco aulas con un despacho adjunto para el profesor y un archivo de material pedagógico; un aula de dibujo; un taller de ajuste; otro de máquinas; unos laboratorios de química; un salón de actos (que a la vez se utilizaría como sala de proyección); una biblioteca y un núcleo de dirección ${ }^{62}$. Analizando la documentación generada en el estudio del arquitecto en los distintos proyectos presentados al Ministerio de Educación podemos ver como se otorgó un gran protagonismo al estudio del programa del edificio como fase previa para analizar los espacios y enlaces que necesitaba, estudiando con detalle cada uno de los elementos por separado siguiendo un programa de usos, iluminación, acústica, buscando la orientación adecuada y su ubicación con respecto al resto del conjunto ${ }^{63}$.

\footnotetext{
54 Idem.

55 Ibidem, p. 198.

56 Carlos María VAlCÁRCEL, “Concurso de institutos Laborales: Presentación”, Revista Nacional de Arquitectura n ${ }^{\circ} 153$ (1954), p. 1.

57 Miguel Fisac, “Instituto Laboral en Daimiel”, Revista Nacional de Arquitectura, n ${ }^{\circ} 139$ (1953), pp. 3-14.

58 "Alzado y bocetos de edificio para instituto laboral en Daimiel" (1950). Archivo de la Fundación Miguel Fisac

59 "Carta de Miguel remitiendo el proyecto al subsecretario del Ministerio de Educación Nacional fechada el 30 de abril de 1951”. Archivo de la Fundación Miguel Fisac.

60 “Carta enviada por el Jefe de Sección al arquitecto Miguel Fisac fechada el 5 de mayo de 1951". Archivo de la Fundación Miguel Fisac.

61 "Memoria. Proyecto de edificio para instituto laboral en Daimiel" (1951). Archivo de la Fundación Miguel Fisac.

62 Idem.

63 Al final de la memoria del edificio se incorporaron como anexos los estudios de cada uno de los espacios del edificio y un esquema de las conexiones necesaria entre ellos.
} 
Posteriormente el arquitecto realizó la ordenación de los elementos distribuyendo el edificio en dos partes bien diferenciadas: por un lado, un grupo de aulas unidas por una larga galería y por otro una zona compuesta por talleres ${ }^{64}$ (fig. 3). Ambas se unieron en el salón de actos donde también se encontraba la zona de dirección. Dentro de estos espacios individualizados destacó el salón de actos, de planta trapezoidal y centro vital del edificio, ya que servía de nudo de enlace con el resto de dependencias y de entrada a las mismas. Junto al acceso se encuentra un pequeño cuerpo

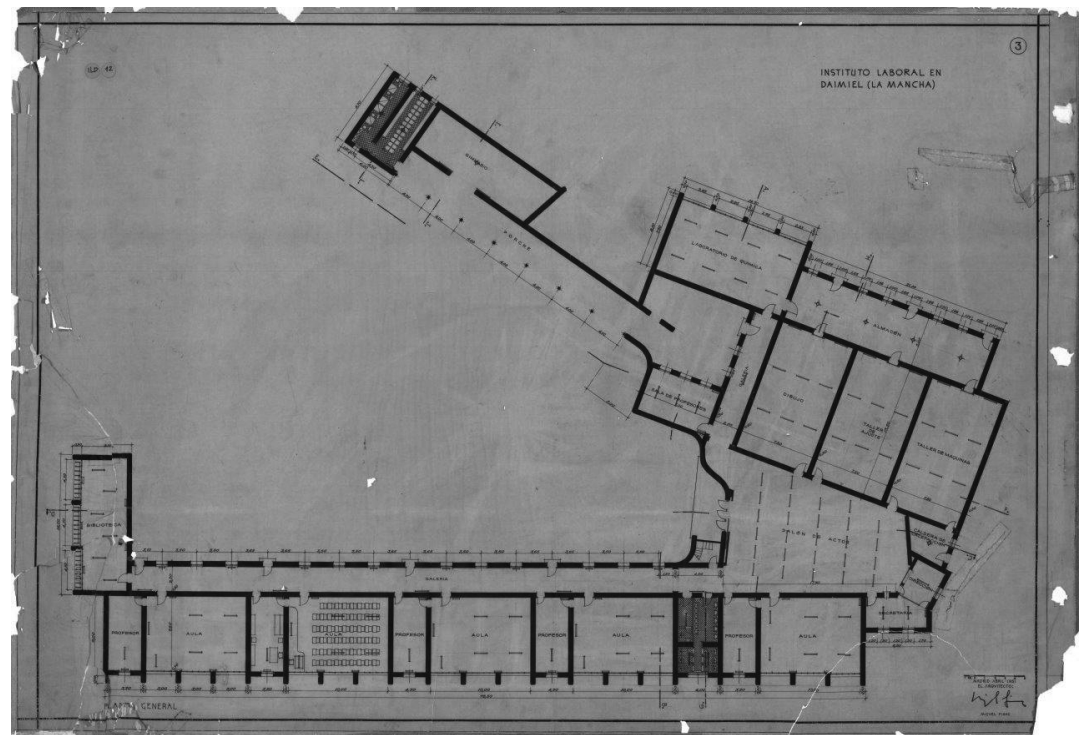

Fig. 3. Miguel FISAC, planta de edificio para Instituto Laboral en Daimiel, 1951. Archivo de la Fundación Miguel Fisac. donde está la escalera de acceso a la cabina de proyección dispuesta sobre la embocadura de la galería de aulas ${ }^{65}$. Debido a su utilización como hall se ocasionaron algunos problemas funcionales, ya que la cabina de proyección debía de situarse en un lugar que no perturbase la entrada del edificio y al desplazarla se producía una deformación en los visionados cinematográficos. Para corregir este defecto el paramento del salón donde se situaba la pantalla de proyección se colocó de forma que era normal a la bisectriz que formaba el eje general de la sala con el eje de proyección, mejorando todos los puntos de vista ${ }^{66}$. Las cubiertas del salón se sustentaron con una serie de cerchas metálicas que marcaban el aspecto exterior en el edificio y se cubrieron con tablero de fibra tipo Táblex. Estaban dotados con unas trampillas móviles que permitían el oscurecimiento de los lucernarios accionados mecánicamente ${ }^{67}$ (figs. 4 y 5). En el proyecto primitivo se había planteado la utilización de corcho como material aislante y de insonorización en los techos de las aulas y salón de actos, sin embargo, cuando apareció en el mercado el nuevo material el arquitecto solicitó al ministerio la ampliación del presupuesto ${ }^{68}$ aumentando el precio final del conjunto en más de 250.000 pesetas $^{69}$.

Las aulas del centro estaban perfectamente estudiadas en cuanto a cuestiones de iluminación, ya que contaban con unos amplios ventanales laterales abiertos al exterior para conseguir la mejor iluminación posible (figs. 6 y 7). El techo destacaba por su silueta curva que sorprende al espectador y que buscaba

64 Miguel FISAC, “Instituto Laboral de Daimiel”, A\&V Monografias: Miguel Fisac, Arquitectura Viva, n 101 (2003), p. 30.

65 En la escalera destaca la barandilla de hierro diseñada por el arquitecto y cuyo pasamanos servía de conducto para el agua.

66 FISAC, 1953, p. 10.

67 "Revisión del presupuesto del proyecto de edificio para Instituto Laboral en Daimiel por mejoras introducidas en el mismo". (1953). Archivo de la Fundación Miguel Fisac.

68 Idem.

69 El presupuesto original aprobado por el ministerio era de 3.183.612,18 pesetas. Se realizaron dos solicitudes de aumento de presupuesto, una primera en una memoria reformada en 1953 por cambio de materiales con un coste de 253.360,21 pesetas y una ampliación del proyecto con un coste $316.138,06$ pesetas. Según se desprende en el informe del Director General de Enseñanza Laboral los costes de las obras fueron financiadas mayoritariamente por el ministerio y existía una partida por parte del Ayuntamiento de Daimiel que se encargaba de financiar 900.000 pesetas del proyecto y cedía los terrenos para su construcción. “Carta del Director General de Enseñanza Laboral a Miguel Fisac fechada el 10 de julio de 1953”. Archivo de la Fundación Miguel Fisac. 


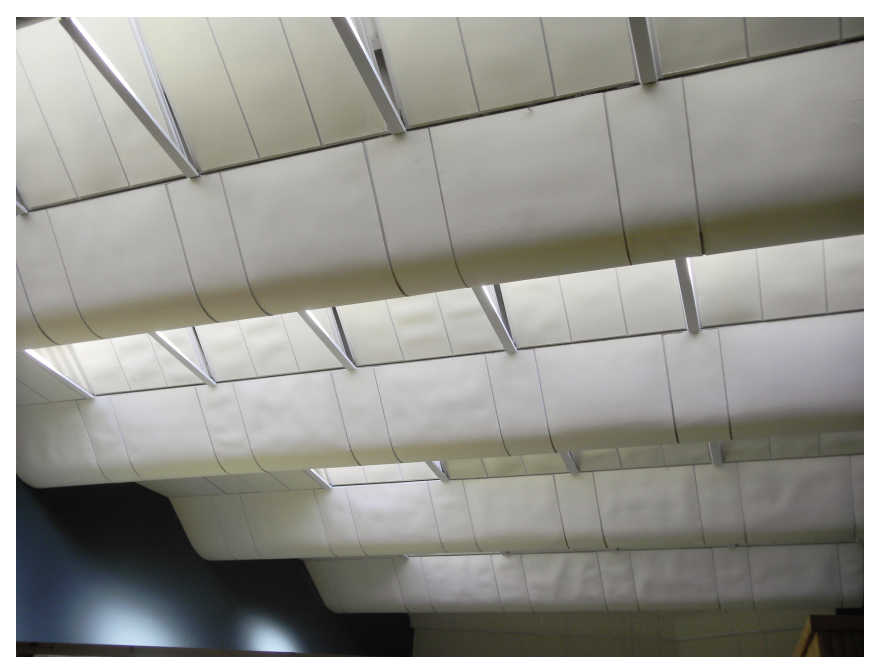

Fig. 4. Miguel FISAC, cubierta del salón de actos en la actualidad. Fotografía del autor.

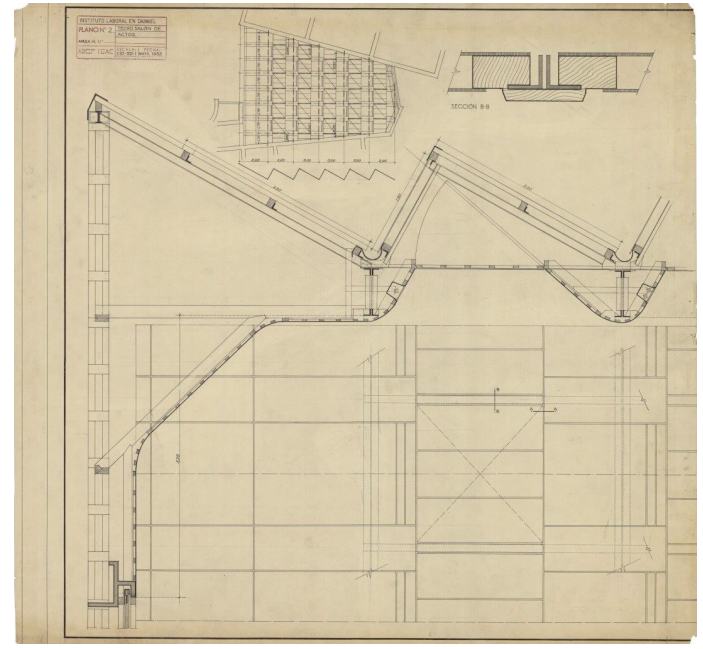

Fig. 5. Miguel FISAC, diseño del techo del salón de actos, 1953. Archivo de la Fundación Miguel Fisac.

conseguir una perfecta dispersión acústica del espacio y al mismo tiempo servía como soporte de unas lámparas fluorescentes que diseñó en 1949 y registró bajo el nombre de "Blancanieves" en $1956^{70}$. Los luminarios conseguían matizar de forma sencilla todo el espacio interior mediante la rítmica disposición de la luz cenital ${ }^{71}$. En uno de los lados menores de las aulas el arquitecto realizó pinturas murales basadas en composiciones geométricas que se inspiraban en paisajes de La Mancha vistos desde altura. Cada una de las pinturas fue ejecutada en una gama distinta de color con la finalidad de representar las cuatro estaciones. Los alumnos no las visualizaban ya que se encontraban de espaldas a ellas con el fin de no distraer su atención.

Alejados del resto de dependencias se encontraban una serie de espacios enlazados por un porche de pies derechos de madera de más de 28 metros de largo por el que se tenía acceso al gimnasio situado en la terminación del mismo ${ }^{72}$, dejando un espacio libre preparado para en el futuro poder instalar allí una pequeña capilla que nunca llegó a construirse ${ }^{73}$. El diseño de este espacio planteaba muchas similitudes con la construida poco después en el Colegio Apostólico de Arcas Reales en Valladolid (fig. 8). En la capilla, los muros laterales opacos tendían a unirse según se aproximaban a la zona del altar que se conjugaba con una elevación progresiva del suelo y techo hacia el presbiterio. El efecto dinámico de la planta de la iglesia se reforzaba aún más con una pequeña puerta lateral dejando atrás la entrada tradicional a los pies de la iglesia. En el otro extremo del porche se ubicó uno de los elementos más poéticos del conjunto. A través de un arco horadado en el muro se daba acceso a un patio al que asomaba la sala de profesores y que estaba configurado por muros encalados, el sonido del agua y una parra ${ }^{74}$, como si el arquitecto hubiera pretendido capturar un pequeño fragmento del paisaje de La Mancha.

\footnotetext{
70 "Memoria descriptiva: Pantalla soporte para tubo de luz" (1956). Oficina Española de patentes y marcas. Modelo de utilidad n 118812 .

71 La solución espacial del diseño de las aulas será repetida en futuros proyectos como el Colegio Apostólico de Arcas Reales o el Centro de Formación del Profesorado en Madrid.

72 "Memoria. Proyecto de edificio para instituto laboral en Daimiel" (1951). Archivo de la Fundación Miguel Fisac.

73 "Esquema de Capilla. Proyecto de edificio para instituto laboral en Daimiel" (1951). Archivo de la Fundación Miguel Fisac.

74 Jaime ApARICIO, 2016, p. 228.
} 


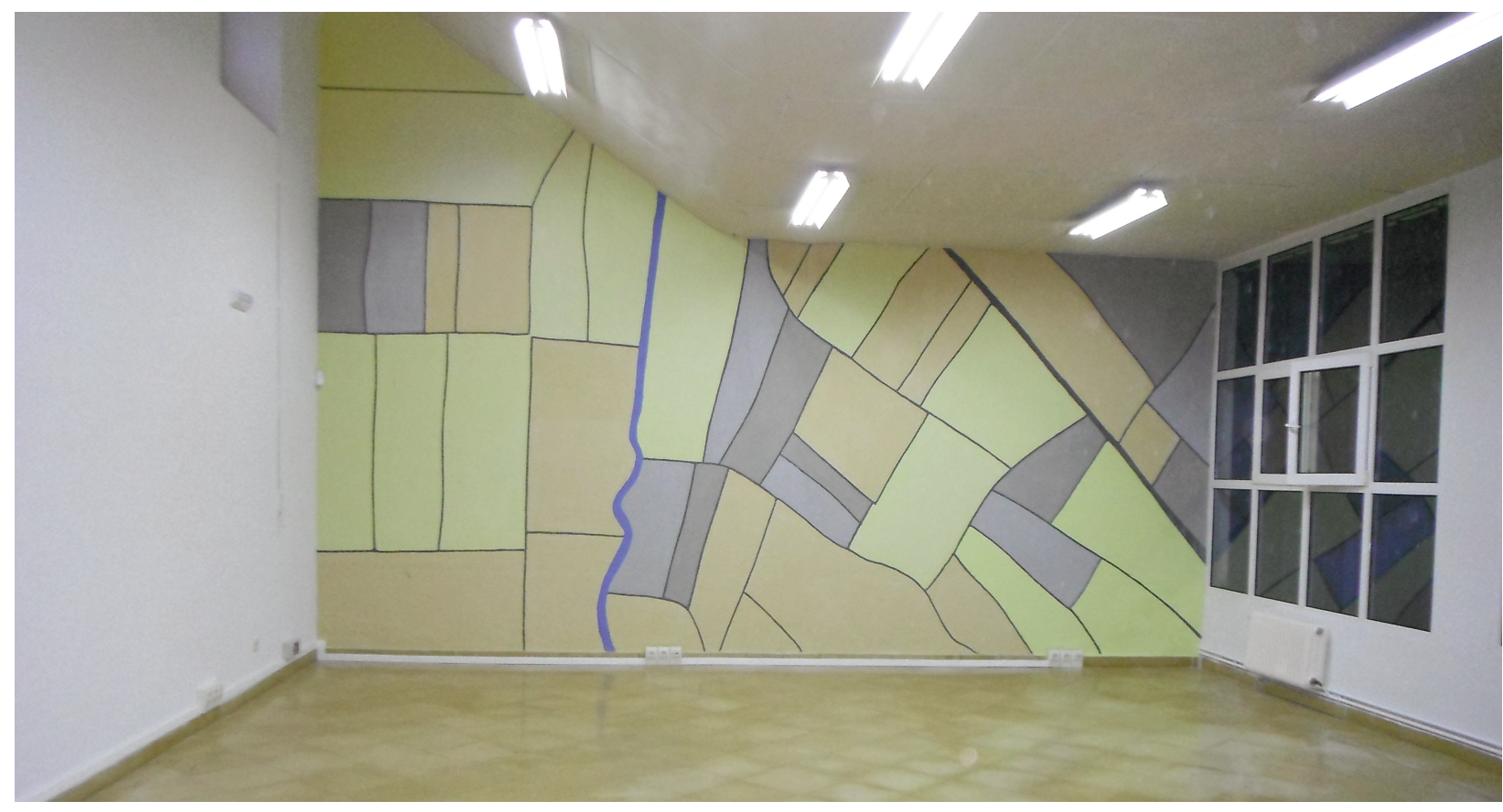

Fig. 6. Miguel FISAC, aula del Instituto Laboral de Daimiel en la actualidad. Fotografía del autor.

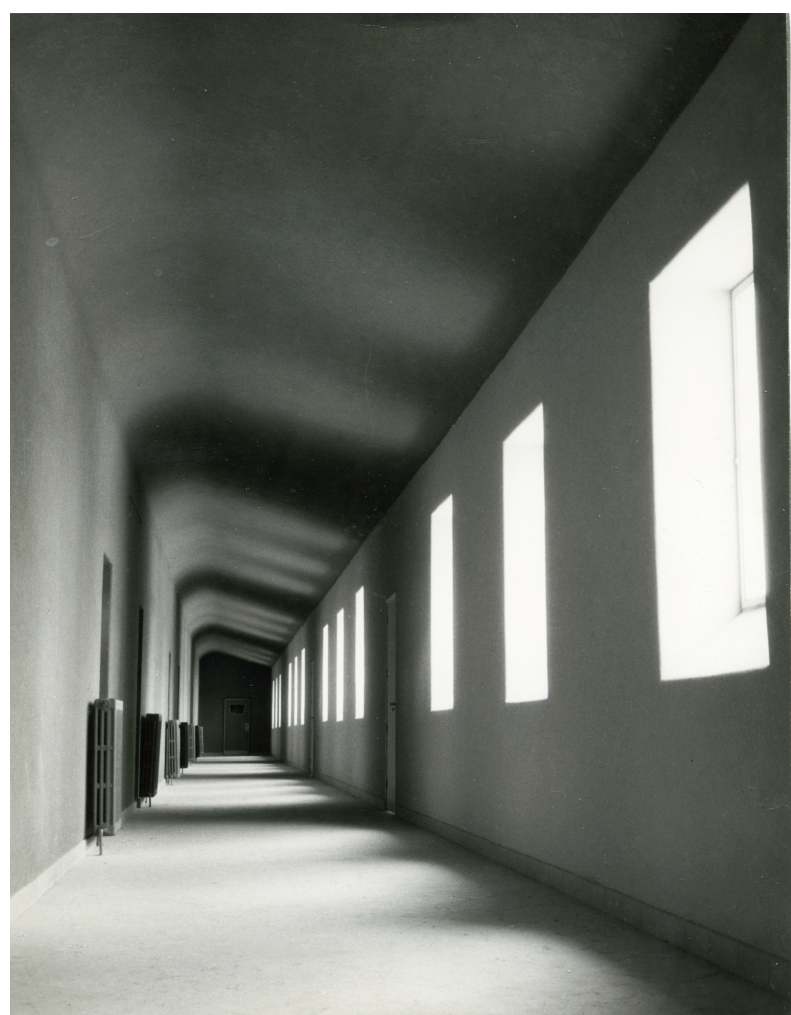

Fig. 7. Miguel FISAC, galeria del Instituto Laboral de Daimiel, 1953. Archivo de la Fundación Miguel Fisac.

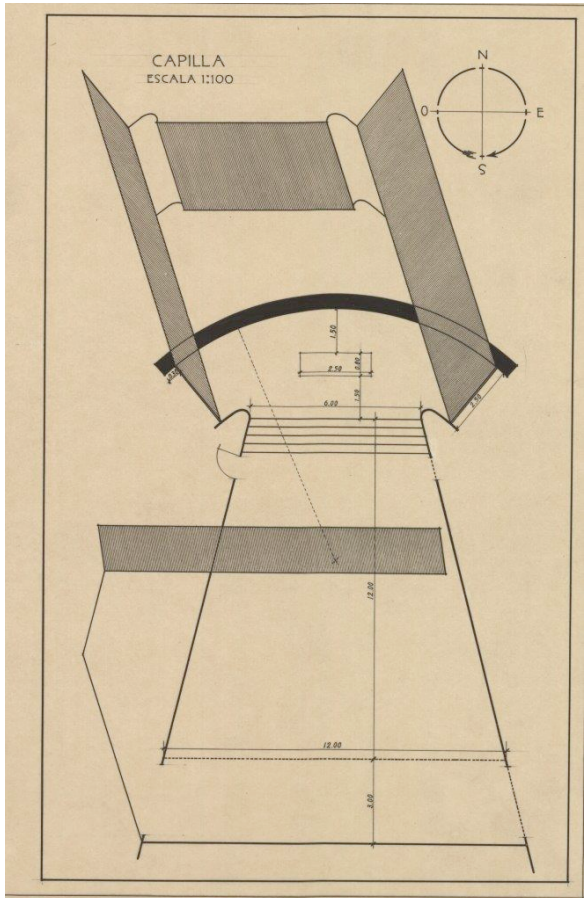

Fig. 8. Miguel FISAC, esquema de capilla. Proyecto de edificio para instituto laboral en Daimiel, 1951. Archivo de la Fundación Miguel Fisac. 


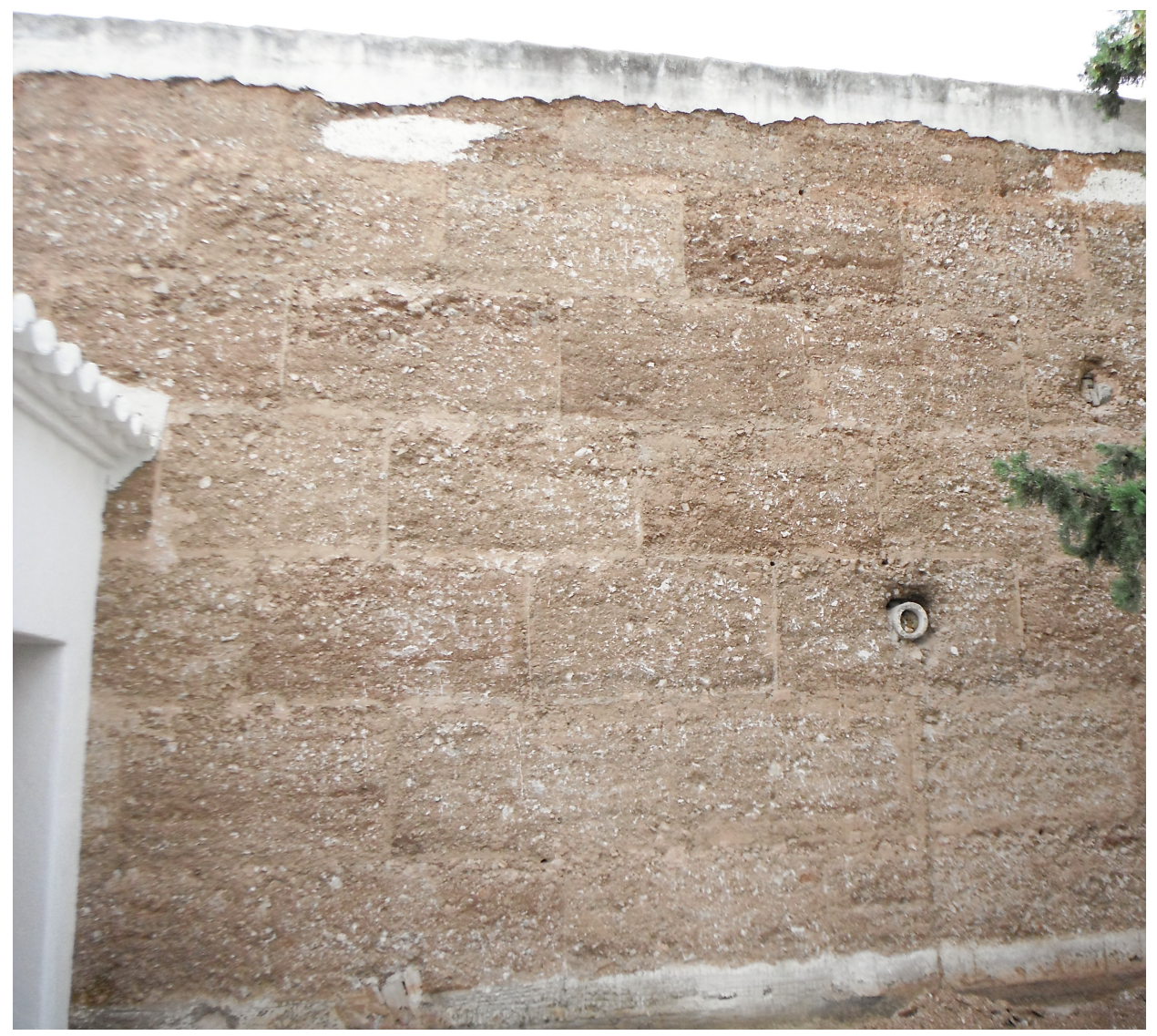

Fig. 9. Miguel FISAC, sistema constructivo de los muros. Fotografía del Centro de Intrepretación del Agua y los Humedales Manchegos (CIAHM).

En el diseño del Instituto Laboral de Daimiel se puso el acento en la relación que se producía entre el edificio y su entorno, buscando la conexión con el lugar ${ }^{75}$. Es frecuente, en varios proyectos del arquitecto, un intenso estudio de la topografía del terreno donde se intentaba respetar los elementos existentes en la medida de lo posible. De hecho, en varios edificios el arquitecto insertó una serie de miradores, balcones o pórticos que buscaban activar ese diálogo con elementos singulares del entorno, mientras que en otros casos creó pequeños rincones cargados de referencias locales como hemos visto en el patio de la sala de profesores.

Otro punto de unión con el lugar fue la elección de los materiales de construcción. El arquitecto partió de una construcción de tapial típica de la zona, pero consiguió sacarle el máximo partido plástico, cambiando el contenido y dotándole de mejores condiciones de habitabilidad e higiene. Se utilizaron muros de carga de fábrica mixta de tapial y mampostería sobre una zanja corrida de hormigón en masa impermeabilizado. Para las cubiertas se utilizó teja curva a un agua a excepción del salón de actos, talleres y aula de dibujo donde fueron en diente de sierra de uralita $^{76}$ (figs. 9 y 10). Con todos estos elementos se crearon una serie de volúmenes de una sola planta donde el encalado se convirtió en el remate estético del edificio. En los muros de tapial se mostraban numerosas texturas y acabados que adelantan la preocupación por el remate de los paramentos exteriores en muchas de sus obras a partir de los años setenta:

\footnotetext{
75 Una muestra de la importancia que el arquitecto otorga al entorno es la existencia de varios planos de emplazamiento de cada proyecto que se conservan en el Archivo de la Fundación Miguel Fisac.

76 "Memoria. Proyecto de edificio para instituto laboral en Daimiel" (1951). Archivo de la Fundación Miguel Fisac.
} 


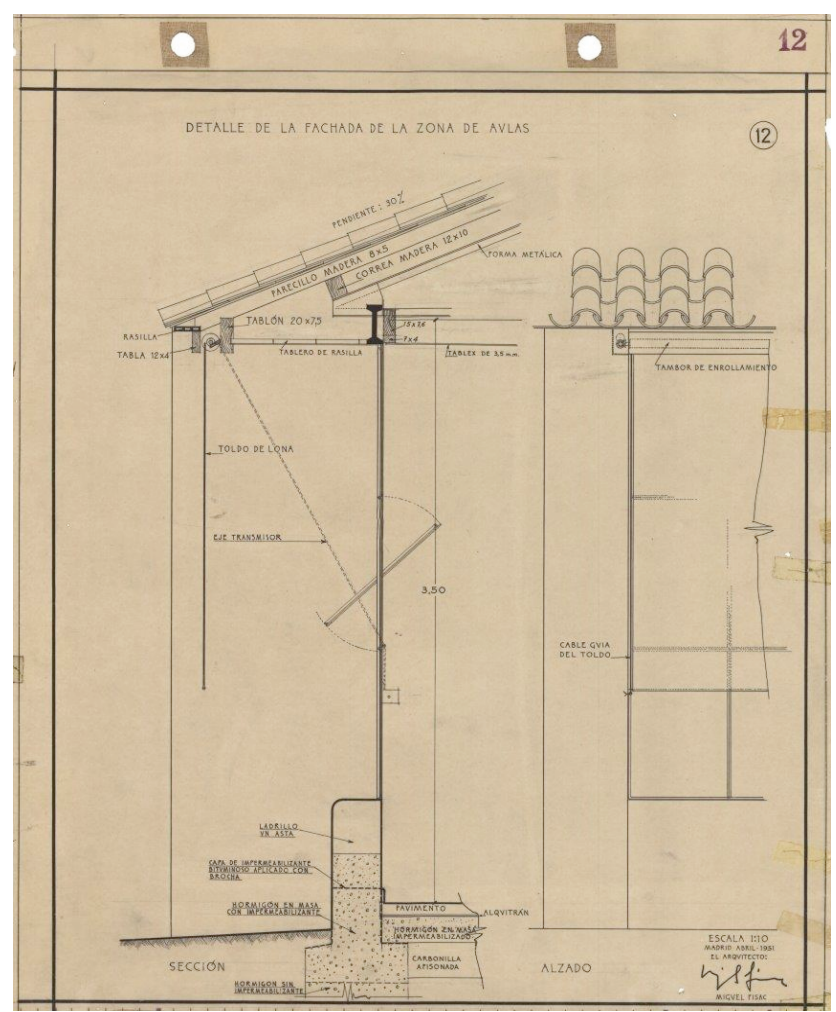

Fig. 10. Miguel FISAC, detalle de la fachada, 1951. Archivo de la Fundación Miguel Fisac.

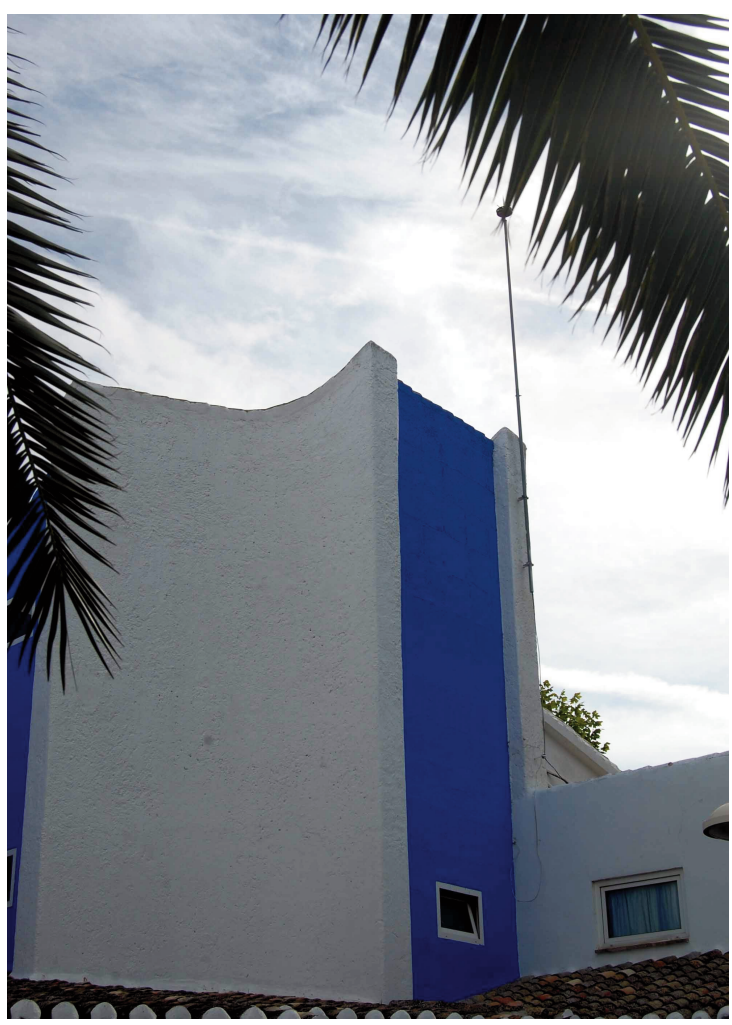

Fig. 11. Miguel FISAC, vista del torreón con decoración de color añil. Fotografía del autor.

Las paredes interiores y exteriores de la casilla se enjalbegaban con cal en su doble misión higiénica y de consolidación de las superficies del tapial. La belleza de esa cal, unida a la preciosa textura que originaban las sucesivas capas blancas al tirársela, generalmente con un cacillo o sartenilla atados a la punta de una caña de tornasol, es la propia estética de un planteamiento programático y constructivo. ${ }^{77}$

La Mancha se convirtió en la verdadera protagonista estética del edificio como quedó patente en la utilización del color añil, elemento muy común en la arquitectura manchega junto al blanco de la cal, pero aquí es utilizado de manera distinta a la tradicional ${ }^{78}$ creando grandes lienzos que emergen del conjunto horizontal del instituto ${ }^{79}$ (fig. 11).

Para completar la vinculación poética con el lugar Fisac diseñó un enorme jardín que acaparó buena parte del protagonismo del edificio ya que servía de espacio de recepción al visitante al carecer el conjunto de la típica fachada principal. El arquitecto mostró en sus proyectos una gran sensibilidad hacia la jardinería y los elementos que configuran los $\operatorname{mismos}{ }^{80}$, influencia del citado viaje a Europa, del redescubrimiento personal de La Alhambra y que se intensificó posteriormente a raíz del viaje que realizó a Japón en 1953. El jardín se incluye dentro del proyecto de ampliación del edificio que fue presentado al ministerio en 1953 y donde queda clara su importancia: "Está integrado este proyecto por obras com-

77 Miguel FISAC, Arquitectura popular manchega, Ciudad Real, Colegio de Arquitectos de Ciudad Real, 2005, p. 19.

78 El añil recibe el nombre del arbusto del que se saca el tinte (añil o índigo) y es usado tradicionalmente en los zócalos de los muros.

79 ApARICIO, 2016, p. 227.

80 Ibidem, p. 208. 


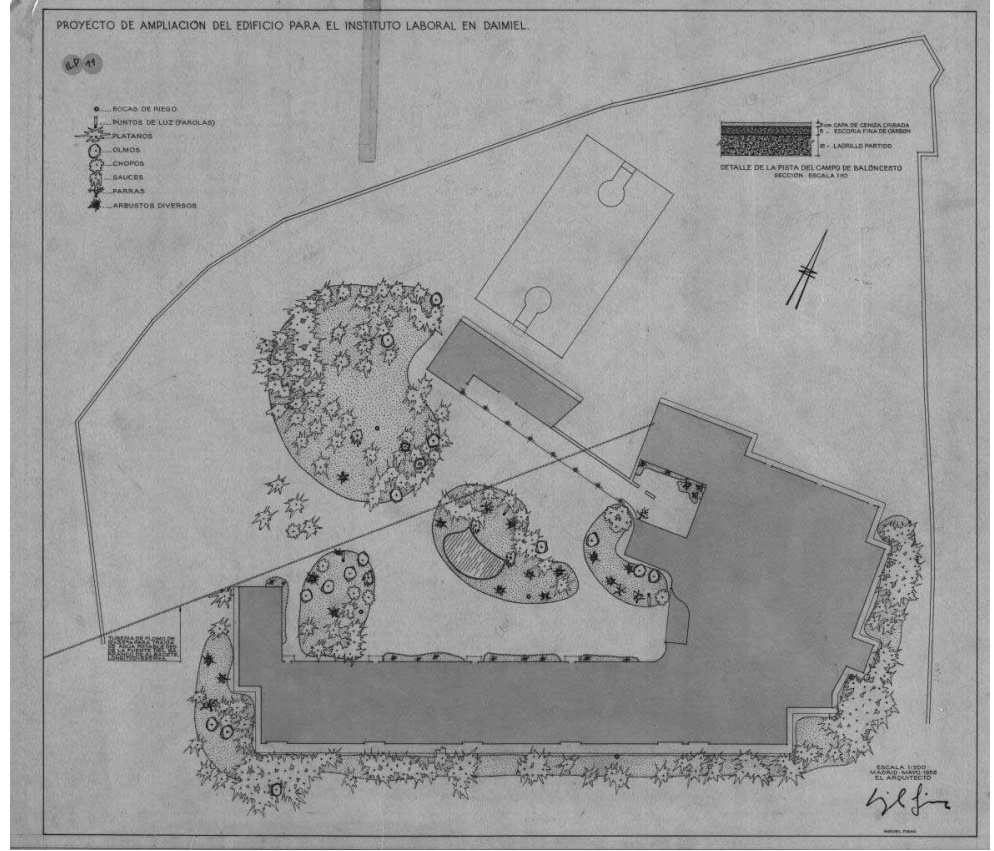

Fig. 12. Miguel FISAC, plano de jardinera del Instituto Laboral de Daimiel, 1953. Archivo de la Fundación Miguel Fisac. plementarias al instituto. Sin embargo, dada la disposición de los diferentes recintos y su directa relación con el exterior, la jardinería, los campos de deportes, etc. no son como un apéndice ornamental, sino que se pueden considerar como parte integrante del propio edificio"81 (fig. 12).

Para la configuración del jardín se utilizaron especies arbóreas de la zona como sauces, chopos, olmos y principalmente plátanos, que se distribuyen en los jardines y en el entorno del espacio construido ${ }^{82}$. En algunas de las zonas bajas de los muros se situaron una serie de arriates de barro encalado donde se plantaron arbustos que evocan directamente a que la arquitectura se aferra a la tierra a la que pertenecen (fig. 13). Miguel Fisac utilizó en muchas de sus obras elementos relacionados con el agua, un

recurso de influencia directa de la arquitectura hispanoárabe. En el caso del Instituto de Daimiel el origen del agua lo encontramos en una original fuente situada en el patio donde el agua manaba de la boca de un cántaro que sobresalía del muro de tapial y descargaba el caudal sobre una tinaja partida. Miguel Fisac la denominó fuente con ruido a dos voces, ya que al caer el agua sobre el pilón daba una nota aguda y luego, al verter esa agua en el suelo, daba otra nota distinta ${ }^{83}$ (fig. 14). Posteriormente el agua circulaba hasta un estanque que estaba inspirado en las riberas del rio Guadiana. A través de estos elementos trataba de evocar paisajes en sus edificios, poniendo en contacto directo la arquitectura con el lugar que la vio nacer.

Uno de los aspectos donde quedó más patente la influencia nórdica del edificio fue en el ejercicio de diseño de todos los elementos que lo configuraban. El arquitecto diseñó la totalidad del edificio y para ello tuvo que recurrir a la colaboración de una serie de artesanos locales ante la inexistencia en el mercado español de muebles y complementos acordes con su estética moderna. El mobiliario constaba de diversas piezas como mesas, estanterías, sillas..., que fueron patentadas por el arquitecto y que destacaron por su diseño sobrio ${ }^{84}$. En los pequeños matices del edificio se puede observar un intenso sabor escandinavo como en el sencillo diseño formado a base de curvas en los picaportes o en los bordes de las puertas ${ }^{85}$. El Instituto Laboral de Daimiel es deudor del momento de su planificación y tiene importantes influencias de Jacobsen y de la fábrica de sazonar arenques en la isla de Sjaellands que Fisac

81 "Proyecto de ampliación del edificio para instituto laboral en Daimiel" (1953). Archivo de la Fundación Miguel Fisac.

82 "Plano de jardinería. Edificio para instituto laboral en Daimiel" (1953). Archivo de la Fundación Miguel Fisac.

83 Miguel FISAC, "El Agua”, Blanco y negro, 10-08-1957, pp. 83-84.

84 "Memoria descriptiva: Un nuevo modelo de mesa y silla escolares" (1952). Oficina Española de patentes y marcas. Modelo de utilidad no ES0031119.

${ }^{85}$ María Paz Aguiló Alonso, “Acerca del diseño: Miguel Fisac y el mobiliario del Consejo Superior de Investigaciones Científicas" en X Jornadas de Arte El arte español del siglo XX. Su perspectiva al final del milenio, Madrid, Consejo Superior de Investigaciones Científicas, 2001, p. 82. 


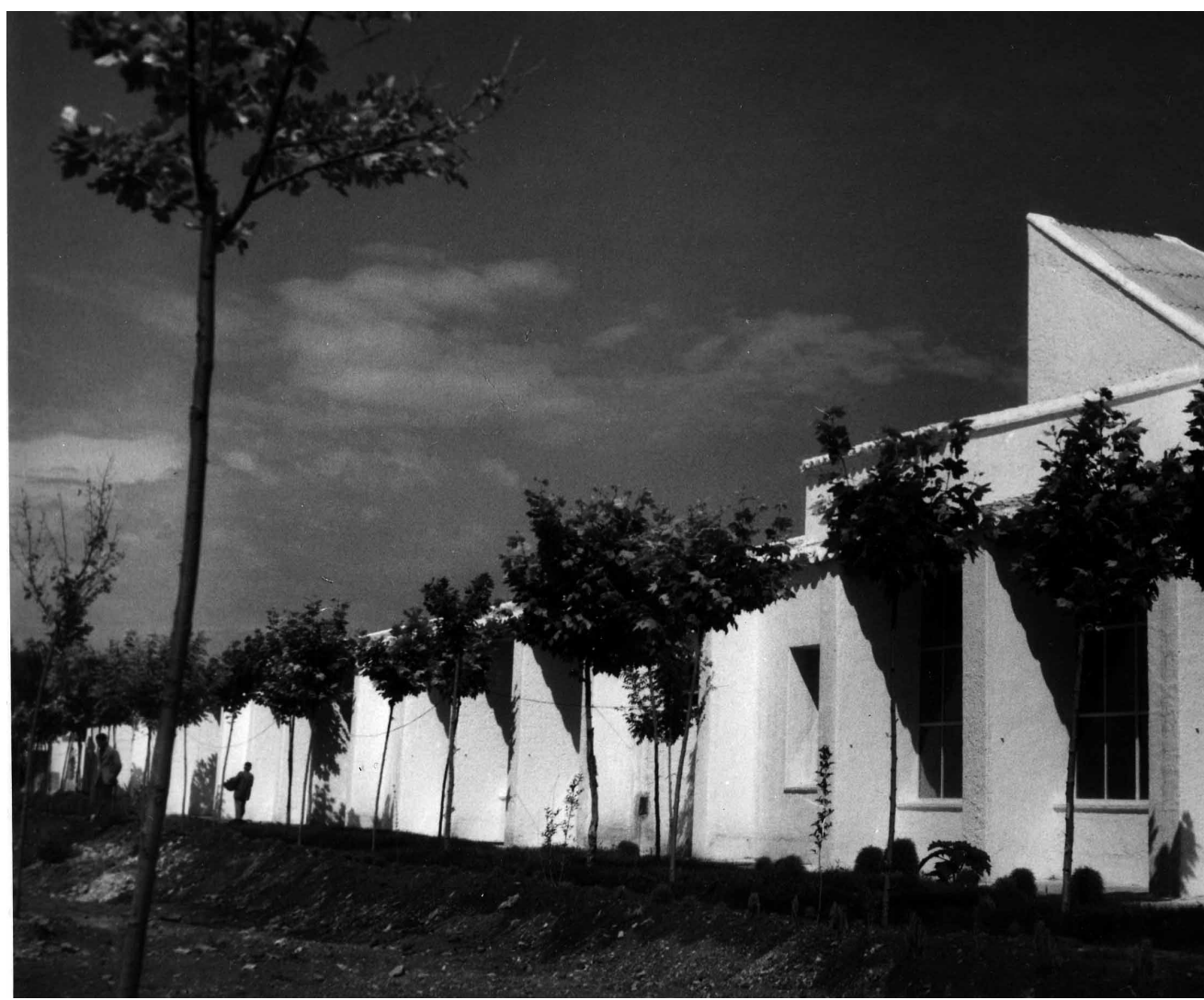

Fig. 13. Miguel FISAC, vista exterior con jardinería del instituto laboral de Daimiel, 1953. Archivo de la Fundación Miguel Fisac.

conoció en su viaje europeo de $1949^{86}$. En Daimiel se visibilizaron, aunque de forma muy básica, algunas de las características de la trayectoria profesional del arquitecto como las siluetas de los huesos en el perfil del salón de actos, la investigación del espacio religioso, la integración de la arquitectura en el entorno, la preocupación por el acabado estético de los muros y el diseño de un modernísimo mobiliario, entre otros.

El edificio fue fríamente acogido por parte de la población local ya que se esperaba una arquitectura de corte monumentalista. Varias décadas después, debido al crecimiento del número de alumnos en la localidad, se construyó un nuevo edificio derribando algunas dependencias del conjunto original sin tener ninguna sensibilidad con el diseño de Miguel Fisac. El resto del edificio con el paso del tiempo quedó inutilizado por parte de la institución educativa. Esta situación generó que se llegara a una situación de completo abandono y casi de ruina en los inicios de la década de los noventa. Es entonces cuando el Ayuntamiento de Daimiel decidió poner fin a este panorama e inició un proceso de rehabilitación de parte del edificio que fue de gran dificultad técnica en algunas ocasiones como en el caso de la recuperación de las cubiertas. En el año 1996 volvieron a abrir sus puertas las dependencias que quedaban en pie del Instituto Laboral albergando en su interior las oficinas del Parque Nacional de las Tablas de Daimiel y el Centro de Interpretación del Agua y de los Humedales Manchegos.

${ }^{86}$ María de las Nieves Cabañas Galán, Convento dominico de Miguel Fisac en Madrid. El acento de los objetos, Tesis Doctoral, Universidad Politécnica de Madrid, 2014, p. 381. 


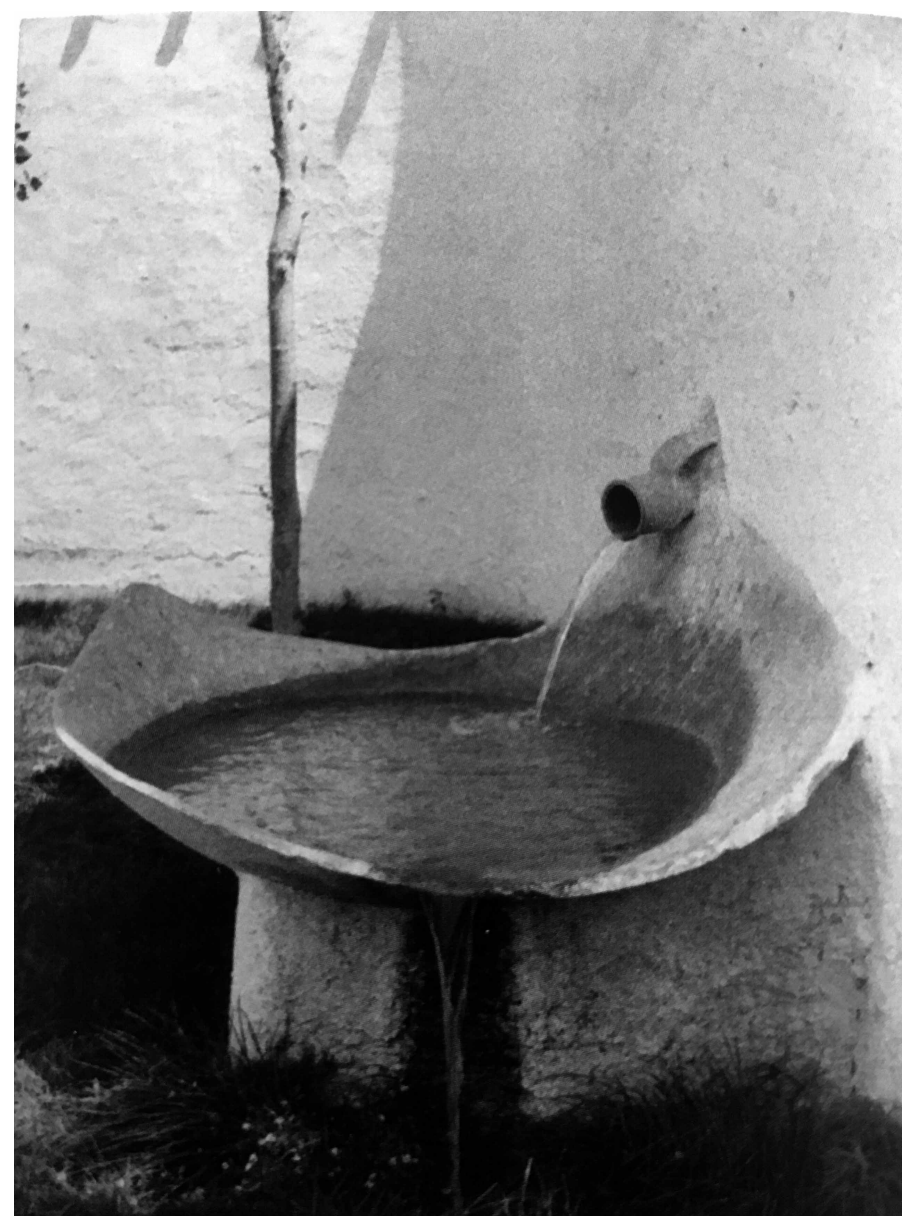

Fig. 14. Miguel FISAC, fuente del instituto laboral de Daimiel, 1953. Archivo de la Fundación Miguel Fisac.

\section{Lo popular como imagen institucional: La Feria del Campo}

Miguel Fisac volvió a recurrir a la arquitectura popular para el diseño del Pabellón de Ciudad Real en la Feria del Campo en Madrid. Se trató de un proyecto de pequeña escala, pero de una gran importancia, construido en 1953 cuando el arquitecto estaba en pleno proceso de construcción de la serie de los institutos laborales, siendo heredero y continuador de la propuesta anterior. En la Feria del Campo de Madrid existen múltiples pabellones basados en la arquitectura tradicional firmados por algunos de los arquitectos españoles más influyentes del momento como Ruiz Cabrero, Secundino Zuazo, Miguel Fisac, etc. ${ }^{87}$

La feria fue organizada por la Organización Sindical, abriendo sus puertas por primera vez el 27 de mayo de 1950. Dos años antes, la Delegación Nacional de Sindicatos habían realizado un encargo a los arquitectos Jaime Ruiz y Francisco de Asís Cabrero para urbanizar la zona y realizar los pabellones principales. Debido al éxito de la primera edición se inició un periodo de ampliaciones y construcción de nuevos pabellones. En 1953 tuvo lugar la segunda edición en la que la feria paso tener carácter internacional, contando con exposi-

\footnotetext{
87 Ángel UrRUtia, "La arquitectura para exposiciones en el recinto de las Ferias del Campo de Madrid (1950-1975) y los antiguos pabellones de IFEMA", Anales del Instituto de Estudios Madrileños, no 35 (1995), pp. 177-196.
} 
tores de Alemania Federal, Austria, Bélgica, Dinamarca, Estados Unidos, Francia, Holanda, Inglaterra, Italia, Portugal, Suecia y Cuba. Algunas provincias españolas también construyeron sus pabellones ofreciendo un complejo repertorio estético inspirado en lo popular que fue desde reproducciones fieles de algunos monumentos históricos como la Puerta Nueva de Bisagra en el caso de la provincia de Toledo o la Torre de Bujaco de Cáceres, hasta soluciones constructivas que partiendo de lo popular reconduciendo su diseño hasta formas más modernas donde estaban las propuesta de José Luis Romaní en el Pabellón de Jaén (1953), de Alejandro de la Sota en el de Pontevedra (1956) o de Miguel Fisac en Ciudad Real (1953).

El local elegido para el pabellón manchego fue un solar complejo, de forma quebrada, que conectaba con dos calles del ferial. La misión del edificio era representar a la provincia mostrando los productos relacionados con el mundo agrícola, con la intención de traer el

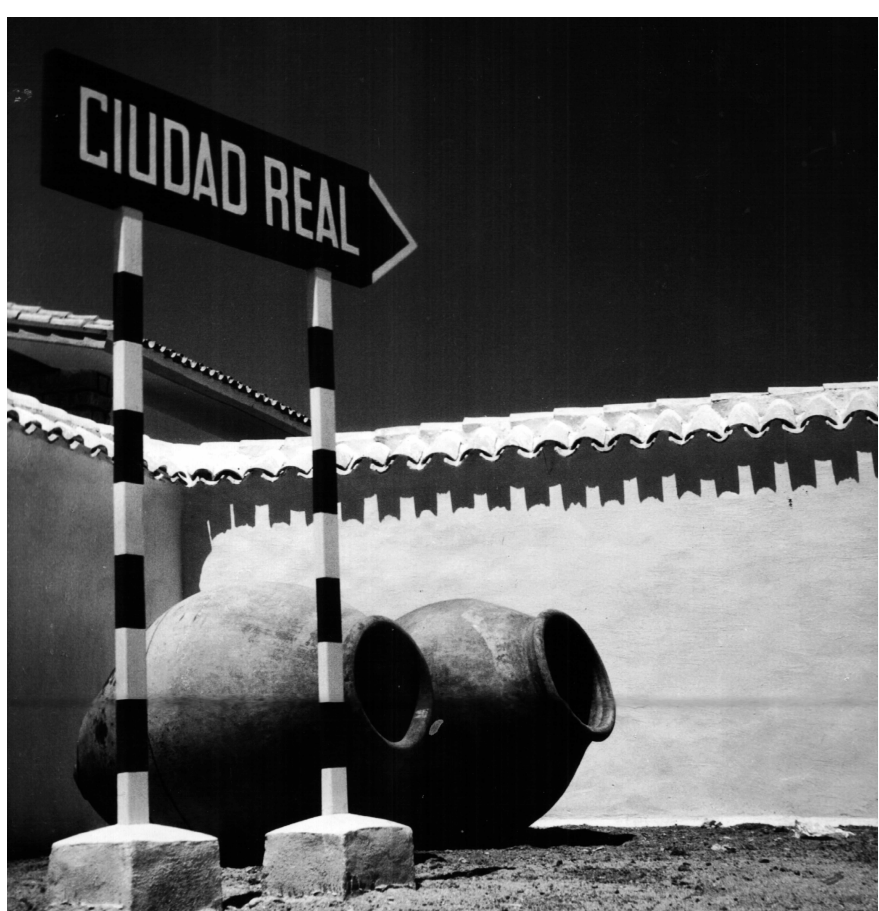

Fig. 15. Miguel FISAC, entrada al Pabellón de Ciudad Real en la Feria del Campo, 1953. Archivo de la Fundación Miguel Fisac. campo a la ciudad, algo muy en consonancia con las ideas del régimen. Se organizó espacialmente las distintas zonas que componiendo el pabellón en torno a dos patios donde se ubicaban una zona de exposición de maquinaria industrial, otra de muestra de productos agrícolas, una tercera de productos ganaderos y por último una zona de despachos. El proyecto se construyó en tan sólo unos meses y se trató de un curioso pabellón totalmente distinto al resto, organizado en torno a los patios comunicados entre sí generando una planta muy sugerente. El edificio se mantuvo en pie hasta el año 1975, aunque muy modificado sobre todo en las últimas ediciones de la feria.

Fisac, que en este proyecto contó con la colaboración de Germán Valentín Gamazo, partió de lo que él consideraba la esencia de la arquitectura popular (en este caso manchega) realizando una reinterpretación de dos construcciones típicas de la zona: la casilla y la quintería. El arquitecto liberó los patios del típico pozo central, creando dos grandes piezas casi vacías en torno a las que se organizaban los distintos espacios que necesitaba el pabellón. Todas las piezas arquitectónicas quedaban situadas en los perímetros de los patios dejando liberado un gran espacio vacío en el centro que se convertía en el verdadero protagonista.

Al recinto se accedía mediante un deslizamiento de dos tapias de tres metros de altura, que servía para aislar el pabellón del exterior y buscaba la visión diagonal de los dos patios por parte del espectador cuando entraba al recinto. Tan sólo un cartel de carretera con el nombre de Ciudad Real orientaba al visitante, evitando en todo momento la típica fachada monumental a la que recurrieron otros pabellones (fig. 15).

En el interior diseñó un jardín formado por una noria, varios chopos y un canal de agua que circula desde el primero de los patios hasta una alberca situada en el segundo, sirviendo de guía al visitante que debía de seguir el curso del agua. Tapial, cal, higuera, chopos, noria, tinajas..., son elementos utilizados para evocar un paisaje, pero no de una manera figurativa, sino que plantea visiones modernas del mismo ${ }^{88}$.

88 José COCA LEICHER, "La arquitectura popular y el paisaje como "materia" de proyecto" en La materia de la arquitectura: I Congreso Internacional de Arquitectura de la Fundación Miguel Fisac, Madrid. Fundación Fisac, 2010, pp. 241-250. 


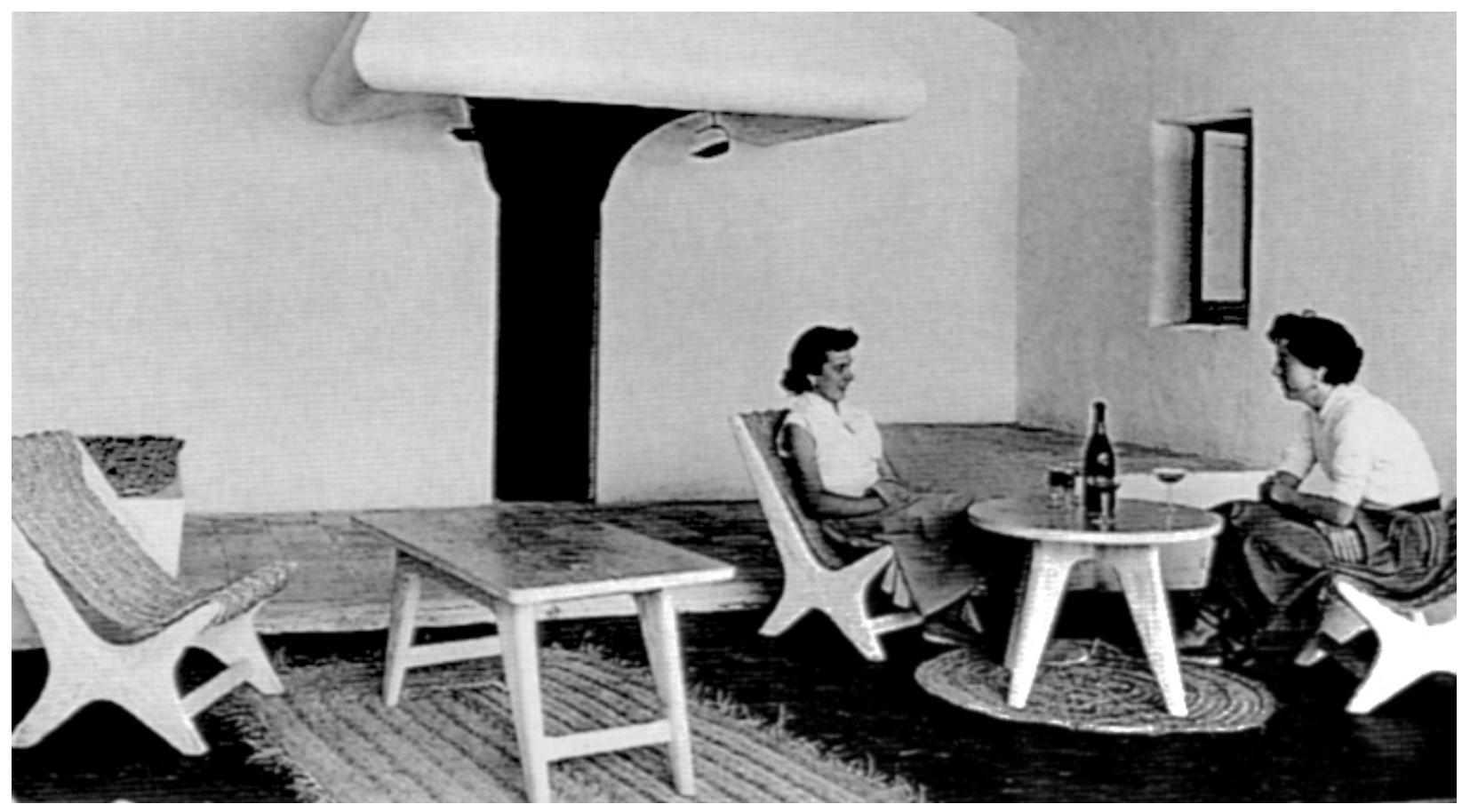

Fig. 16. Miguel FISAC, mobiliario del Pabellón de Ciudad Real en la Feria del Campo, 1953. Archivo de la Fundación Miguel Fisac.

El objetivo perseguido por Miguel Fisac era transmitir la esencia de lo manchego a través de una recreación intencionada y abstracta del paisaje, una aproximación mediante la interpretación artística de elementos reales. El secreto de la propuesta se encontraba en la búsqueda de la esencia de lo popular eliminando todo aquello innecesario ${ }^{89}$.

Uno de los aspectos más sorprendentes del pabellón, y donde más quedó patente la influencia nórdica del conjunto, fue en el ejercicio de diseño del mobiliario, donde se tomó como punto de partida elementos del mobiliario tradicional pero que resultaban rabiosamente modernos por la sinceridad con la que se trabajó con los materiales, siendo un ejemplo más de que el desarrollo de la arquitectura moderna en España estuvo ligada a la historia del mobiliario ${ }^{90}$. Algunas de las piezas son deudoras del mobiliario y las técnicas utilizadas previamente en la Librería Científica del CSIC en Madrid (fig. 16).

Durante la realización del Instituto Laboral de Daimiel y del Pabellón de Ciudad Real, el arquitecto empezó a utilizar su particular método proyectual. El programa se basó en la realización de un itinerario mental buscando soluciones constructivas a las necesidades del edificio ${ }^{91}$. Se basaba en las preguntas por el "dónde", el "qué", y el "cómo", que conducían a un interés por cuestiones sobre el lugar, la técnica y la funcionalidad ${ }^{92}$. En primer lugar, Miguel Fisac tomaba una actitud previa de intentar mantener en blanco su mente al comienzo del proceso de trabajo, dejando así de lado toda influencia de lo que había visto antes. En segundo lugar, organizaba espacialmente las necesidades del programa. Es decir, estudiaba $34-45$

89 José COCA LEICHER, “Fragmentos de paisaje y arquitectura” en REVISTA Proyecto, Progreso, Arquitectura, n 2 (2010), pp.

90 Sonsoles Caruana Moyano, "La fortuna del mueble español en el mercado de arte como reflejo de su valoración social", Revista de Dialectología y Tradiciones Populares, $\mathrm{n}^{\circ} 1$ (2011), p. 220.

91 Francisco Arqués Soler, Miguel Fisac, Madrid, Pronaos, 1996, p. 37.

92 Luis Fernández Galiano, "Muere Fisac un referente de la elegancia", El País, 12-V-2006, p. 37. 
“¿para qué?” se construía el edificio. Una vez que había obtenido un organigrama de los espacios necesario era necesario analizar las circunstancias en las que se iba a insertar el edificio, estudiar el entorno del que formaba parte: "¿dónde?", era un elemento clave y verdadero protagonista de las obras que acabamos de estudiar con antelación. En este sentido Fisac fue muy crítico con algunos miembros del Movimiento Moderno por el desprecio que tenían hacia el lugar donde construían sus obras. En tercer lugar, con la información obtenida de los anteriores pasos, se planteaba con qué estructura y forma se llevaba a cabo, respondiendo así a la pregunta “¿cómo?”. Este es uno de los puntos donde influían muchos factores como el tipo de material a utilizar, las condiciones económicas del proyecto, etc. Por último, Fisac aplicó su sello personal que él definió como "un no sé qué", que configuraba el resultado final del edificio.

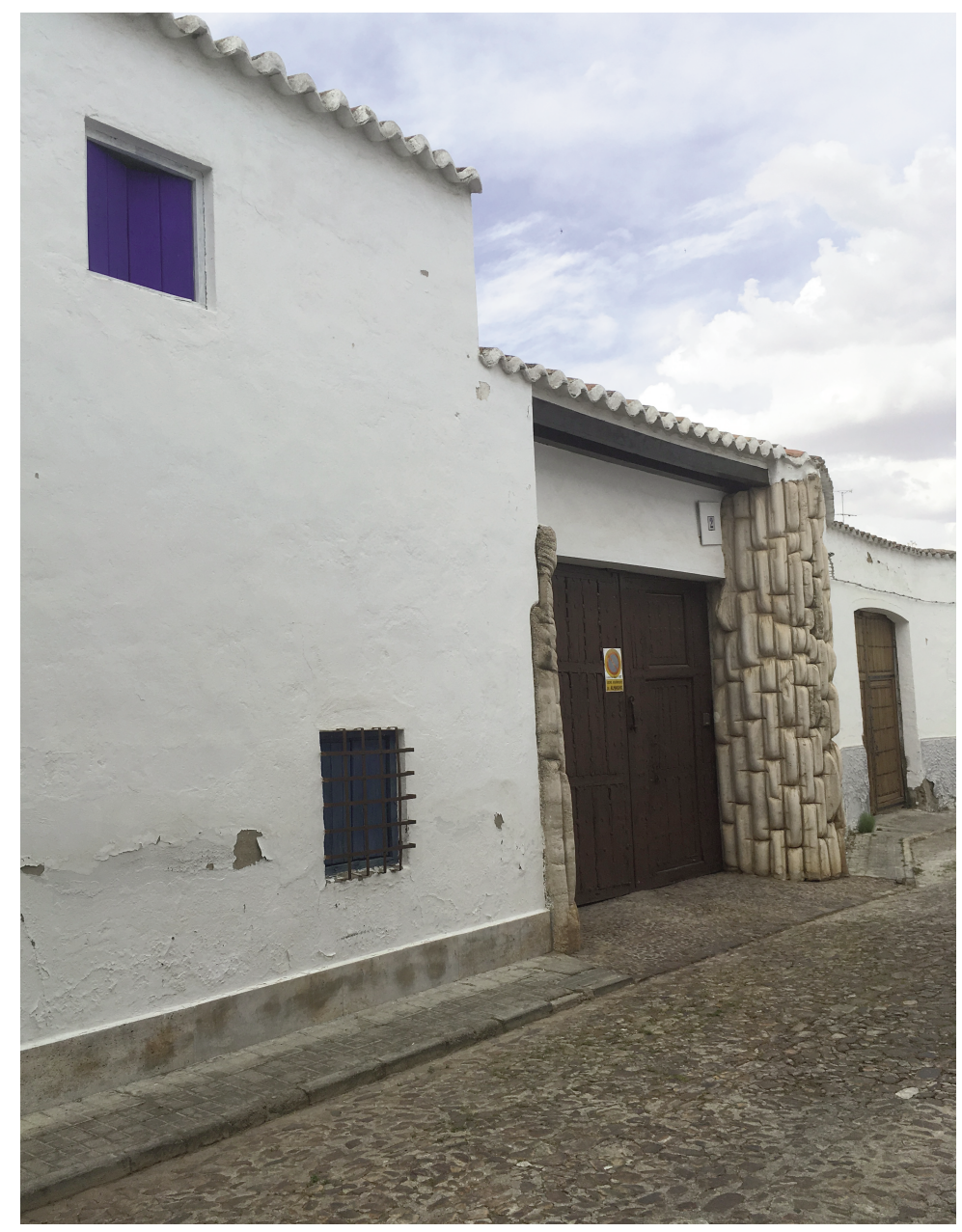

Fig. 17. Miguel FISAC, vivienda familiar, 1978. Almagro (Ciudad Real), fotografía del autor.

\section{Epílogo}

Fisac proyectó en 1950 el Instituto Laboral de Daimiel, uno de sus grandes proyectos tras su periplo por Europa junto con el Instituto de Microbiología Ramón y Cajal y la Librería Científica del CSIC. En él se pueden encontrar una serie de propuestas renovadoras resultado del aprendizaje del viaje y del momento de profunda reflexión en el que estaba inmersa la arquitectura española. Al concluir la obra anterior llevó a cabo el tristemente desaparecido Pabellón del Feria del Campo en Madrid. En ambos proyectos se inició una línea de trabajo que buscó en la arquitectura popular una estética (en un amplio sentido y no solo como material de construcción) válida para el desarrollo de la arquitectura moderna en España. La arquitectura tradicional, y especialmente la manchega, protagonizan buena parte de la obra de Fisac de aquellos años. A través de su arquitectura, escritos, mobiliario o dibujos, el arquitecto hace que lo popular sea una construcción mental evitando en todo momento el costumbrismo. A Fisac le interesa de la arquitectura popular su esencia no su modelo ${ }^{93}$.

93 APARICIO, 2016, p. 83. 


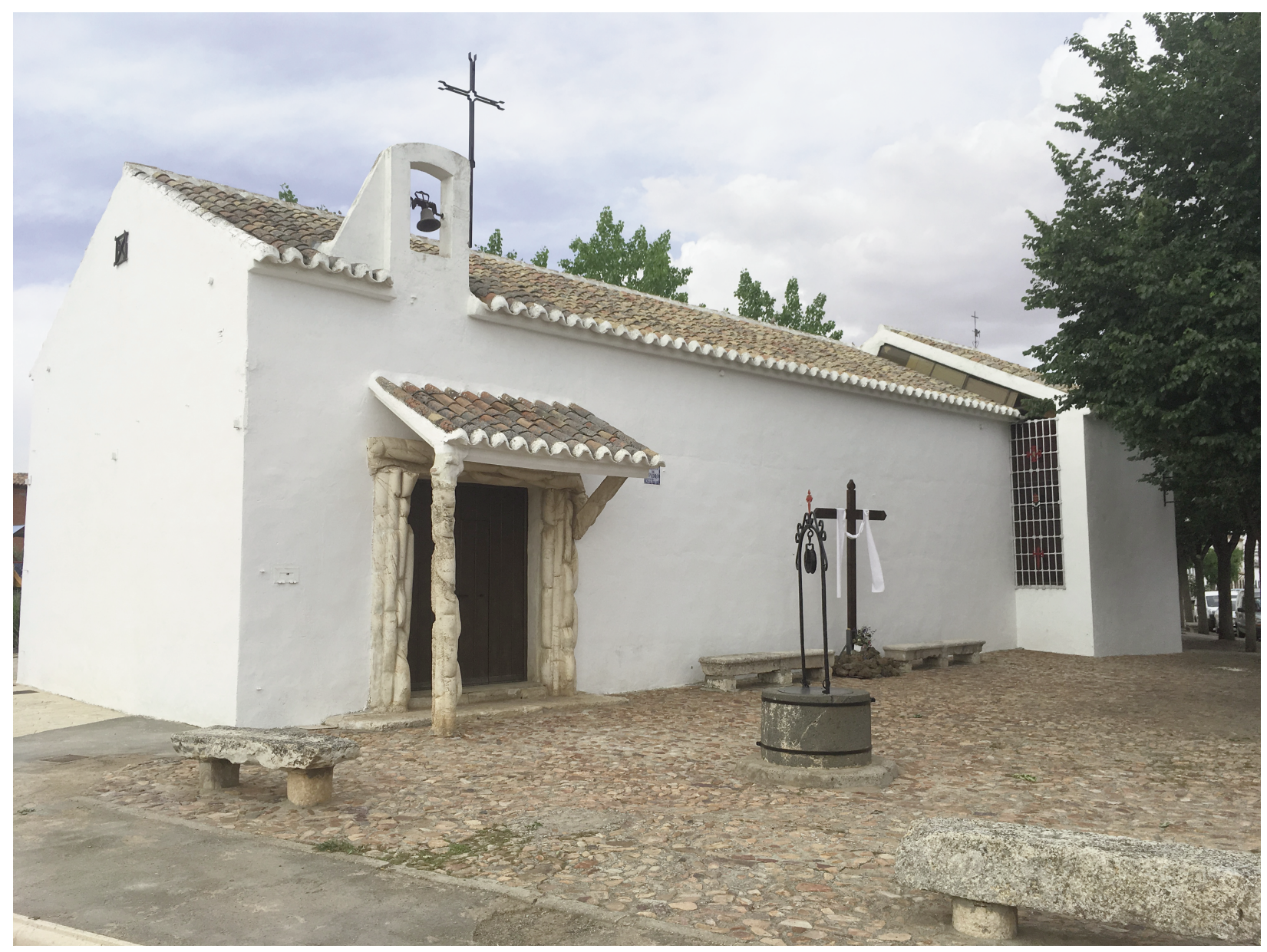

Fig. 18. Miguel FISAC, ermita de San Pedro, 1985. Almagro (Ciudad Real), fotografía del autor.

Las propuestas del arquitecto fueron recogidas en las revistas más importantes del momento y en el libro de Carlos Flores Arquitectura española contemporánea ${ }^{94}$, que en 1961 se publicó como una especie de compendio de la arquitectura moderna en España, donde quedó reflejado el importante papel que el arquitecto y su propuesta tenían en el renovado panorama arquitectónico español. Durante la segunda mitad de la década de los años cincuenta de la mesa del estudio del arquitecto siguieron salieron proyectos que destacaron por una cierta aproximación al racionalismo, pero contaminado con determinados elementos locales. En 1957 construyó la Casa de Cultura de Ciudad Real y en 1958 un mercado de abastos en Daimiel, en ambos proyectos lo popular sigue estando muy presente. En la memoria de este último dejó muy claro su posicionamiento estético:

Las burdas incomprensibles de las gentes que sin formación ni educación estética querrían un edificio exótico, desarraigado de su tierra y de su natural manera de sentir, me veo en la obligación de seguir ese natural, sano, humano y sublime concepto local, no buscando un tipismo, sino actualizando, sin concesiones folklóricas de ninguna clase, la diversidad natural que han de tener edificios enclavados en tierras diversas. ${ }^{95}$

\footnotetext{
94 Carlos Flores, Arquitectura española contemporánea, Madrid, Aguilar, 1961.

95 "Memoria del Mercado de Abastos de Daimiel" (1955). Archivo de la Fundación Miguel Fisac.
} 
Una postura que continuó a lo largo de su dilatada trayectoria como queda patente en algunos de los proyectos de su última etapa, donde sus innovaciones con el hormigón eran formuladas en contextos populares como quedó reflejado en la construcción de su vivienda familiar (1978) y de la ermita de San Pedro (1983) en Almagro (Ciudad Real), donde encontramos sus experimentos con encofrados flexibles de hormigón en fachadas encaladas típicas de la arquitectura tradicional (figs. 17 y 18).

RAMÓN VICENTE DÍAZ DEL CAMPO MARTÍN MANTERO es Doctor por la Universidad de Castilla-La Mancha (2009) y profesor del Departamento de Historia del Arte. Ha participado en varios proyectos de investigación: Arte y Poder en la época contemporánea, la celebración de los XXV años de paz y Las Artes en España de la Transición a la Globalización. Durante su trayectoria investigadora ha realizado investigaciones en el extranjero en la Universidad Iberoamericana en Ciudad de México, Universidad de La Habana y la Universidad de Buenos Aires. Hasta la fecha de hoy son varias sus participaciones en varias revistas, actas de congresos y publicaciones colectivas donde destacan sus trabajos relacionados con el arte español durante la Guerra Civil Española y la Dictadura Franquista. También ha sido comisariado en varias exposiciones temporales.

Email: ramonvicente.diaz@uclm.es 